2015

INTERACTIVE EFFECTS OF CLIMATE CHANGE AND FUNGAL COMMUNITIES ON THE DECOMPOSITION OF WOOD-DERIVED CARBON IN FOREST SOILS

Samantha L. Mosier

Michigan Technological University

Follow this and additional works at: https://digitalcommons.mtu.edu/etds

Part of the Ecology and Evolutionary Biology Commons

Copyright 2015 Samantha L. Mosier

Recommended Citation

Mosier, Samantha L., "INTERACTIVE EFFECTS OF CLIMATE CHANGE AND FUNGAL COMMUNITIES ON THE DECOMPOSITION OF WOOD-DERIVED CARBON IN FOREST SOILS", Master's Thesis, Michigan Technological University, 2015.

https://doi.org/10.37099/mtu.dc.etds/936

Follow this and additional works at: https://digitalcommons.mtu.edu/etds

Part of the Ecology and Evolutionary Biology Commons 


\title{
INTERACTIVE EFFECTS OF CLIMATE CHANGE AND FUNGAL COMMUNITIES ON THE DECOMPOSITION OF WOOD-DERIVED CARBON IN FOREST SOILS
}

\author{
By \\ Samantha L. Mosier
}

\begin{abstract}
A THESIS
Submitted in partial fulfillment of the requirements for the degree of MASTER OF SCIENCE

In Applied Ecology
\end{abstract}

MICHIGAN TECHNOLOGICAL UNIVERSITY

2015

(C) 2015 Samantha L. Mosier 
This thesis has been approved in partial fulfillment of the requirements for the Degree of MASTER OF SCIENCE in Applied Ecology

School of Forest Resources and Environmental Science

Thesis Co-Advisor: $\quad$ Sigrid Resh

Thesis Co-Advisor: $\quad$ Evan Kane

Committee Member: $\quad$ Chad Deering

School Dean: Terry Sharik 


\section{Table of Contents}

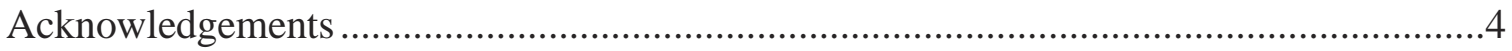

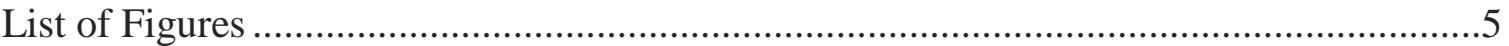

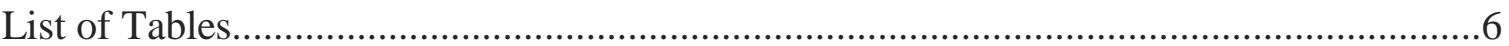

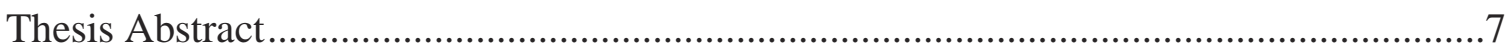

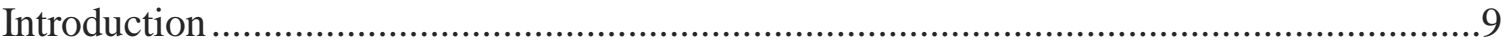

Intro

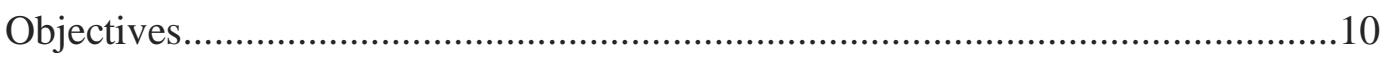

Fungal Community Influences on SOC Losses .....................................................10

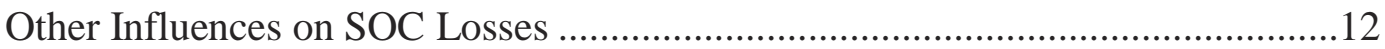

Impacts of Climate Changes …………………………………………………...13

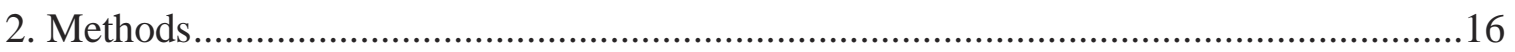

Experimental Design ......................................................................................16

Laboratory Incubations ………………………………....................................19

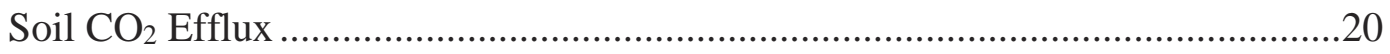

Soil Water Chemistry..................................................................................21

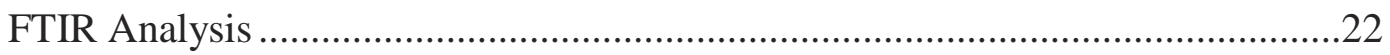

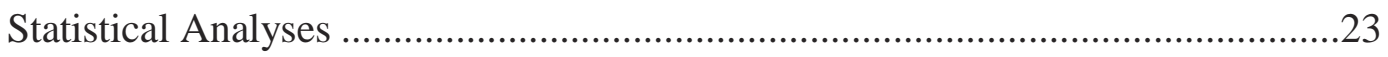

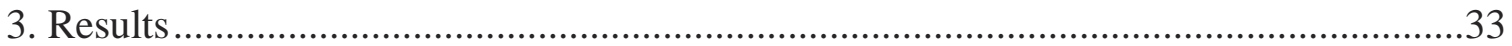

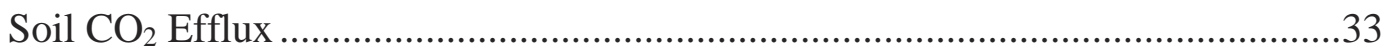

Soil Water Chemistry .........................................................................................36

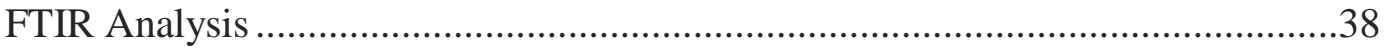

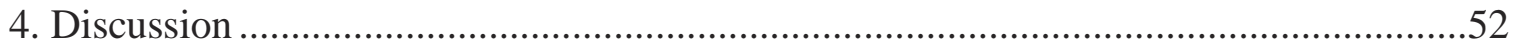

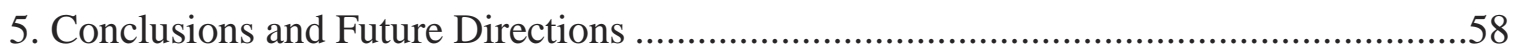

6. Literature Cited ………………………………………........................................60 


\section{Acknowledgements}

This research was supported by the U.S. Department of Energy award \#DE-SC-0006986. I would like to thank my advisors, Drs. Sigrid Resh and Evan Kane, for their continued guidance and support in all things academic and research related during my Master of Science program. Thank you for believing in me and choosing me to work on this project.

I would like to thank the other collaborators on the DOE grant: Dr. Dana Richter, Dr. Erik Lilleskov, Dr. Andrew Burton, and Dr. Marty Jurgesen. If it weren't for their collaboration, this project would never have happened. Thank you all for the input and advice revolving around soils, forest ecology, and fungi.

Thank you to Dr. Chad Deering for serving on my committee.

Thank you to Jennifer Eikenberry for analyzing many of my samples and for constantly helping me to learn and grow as a scientist in the laboratory setting.

I would also like to thank Joe Plowe for helping to set up this project during all stages of preparation.

Thank you to Jim McLaughlin for preforming FTIR analysis on my wood samples. I would like to thank both my field assistants: Andy Buchanan and Sarah Larkin. Field data collection could not have been completed as efficiently without your help. The company was greatly appreciated as well.

Lastly, I would like to acknowledge everyone who worked on the Aspen-FACE project. This study would never have been possible without your wood. Aspen-Face was supported by the U.S. Department of Energy's Office of Biological and Environmental Research, award \#DE-FG02-95ER62125 to Michigan Technological University, and Contract \#DE-AC02-98CH10886 to Brookhaven National Laboratory, the U.S. Forest Service Northern Global Change Program and Northern Research Station, Michigan Technological University, and Natural Resources Canada - Canadian Forest Service. 


\section{List of Figures}

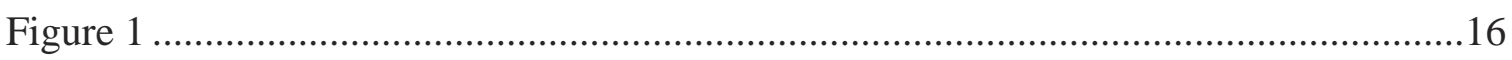

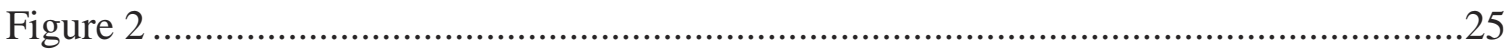

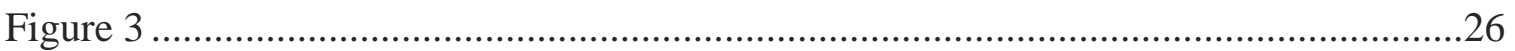

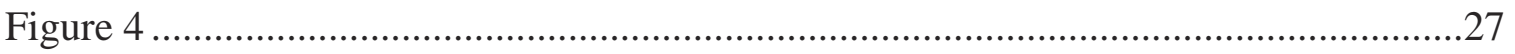

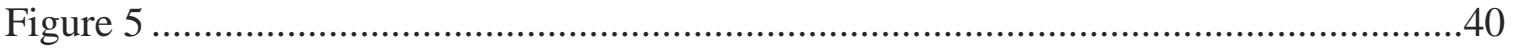

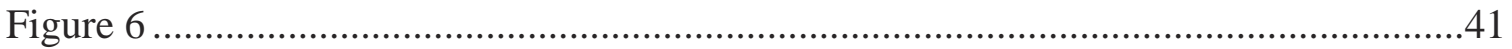

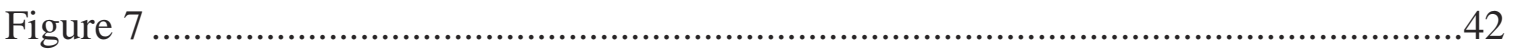

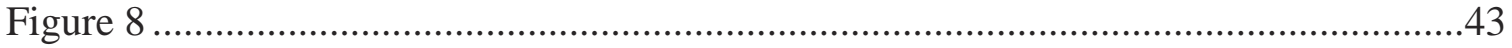

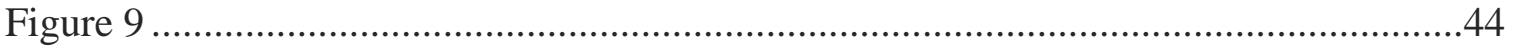

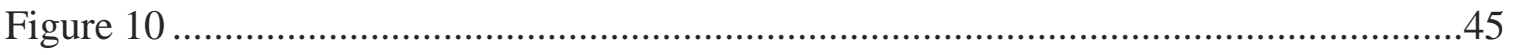

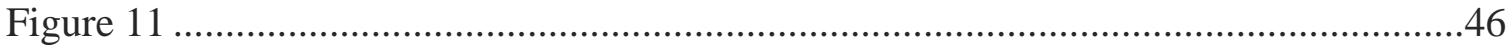

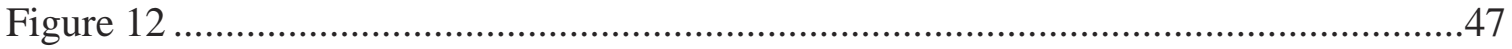

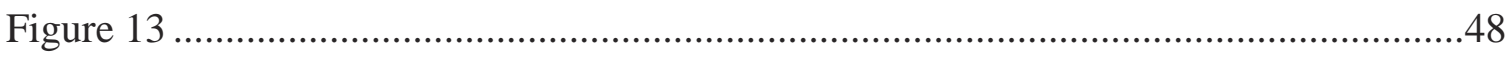

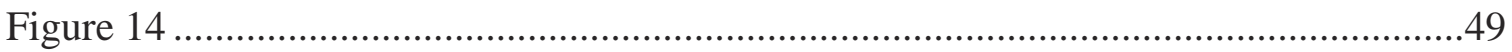




\section{List of Tables}

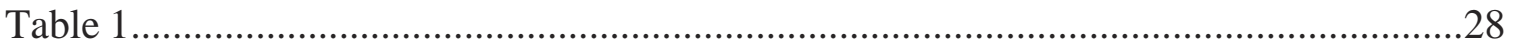

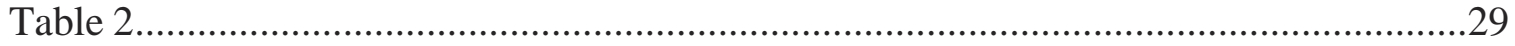

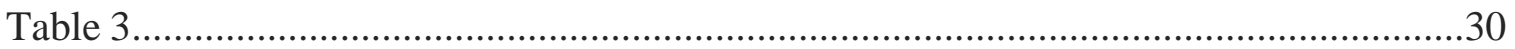

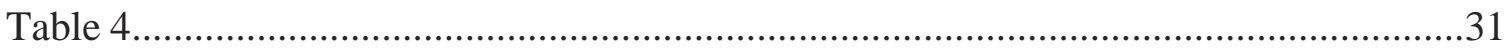

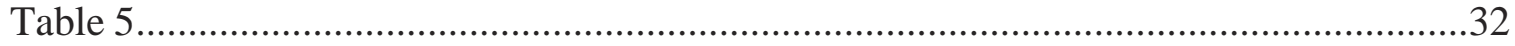

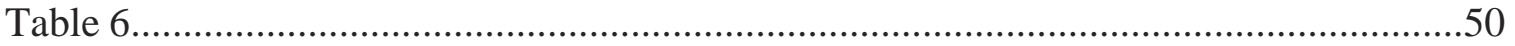

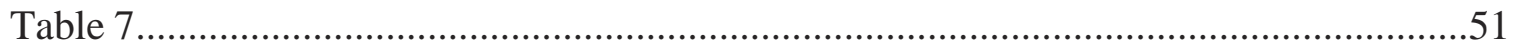




\section{Abstract}

Soils are the largest sinks of carbon in terrestrial ecosystems. Soil organic carbon is important for ecosystem balance as it supplies plants with nutrients, maintains soil structure, and helps control the exchange of $\mathrm{CO}_{2}$ with the atmosphere. The processes in which wood carbon is stabilized and destabilized in forest soils is still not understood completely. This study attempts to measure early wood decomposition by different fungal communities (inoculation with pure colonies of brown or white rot, or the original microbial community) under various interacting treatments: wood quality (wood from $+\mathrm{CO}_{2},+\mathrm{CO}_{2}+\mathrm{O}_{3}$, or ambient atmosphere Aspen-FACE treatments from Rhinelander, WI), temperature (ambient or warmed), soil texture (loamy or sandy textured soil), and wood location (plot surface or buried $15 \mathrm{~cm}$ below surface). Control plots with no wood chips added were also monitored throughout the study. By using isotopically-labelled wood chips from the Aspen-FACE experiment, we are able to track wood-derived carbon losses as soil $\mathrm{CO}_{2}$ efflux and as leached dissolved organic carbon (DOC). We analyzed soil water for chemical characteristics such as, total phenolics, SUVA 254 , humification, and molecular size. Wood chip samples were also analyzed for their proportion of lignin:carbohydrates using FTIR analysis at three time intervals throughout 12 months of decomposition. After two years of measurements, the average total soil $\mathrm{CO}_{2}$ efflux rates were significantly different depending on wood location, temperature, and wood quality. The wood-derived portion soil $\mathrm{CO}_{2}$ efflux also varied significantly by wood location, temperature, and wood quality. The average total DOC and the wood-derived portion of DOC differed between inoculation treatments, wood location, and temperature. Soil water chemical characteristics varied significantly by inoculation treatments, temperature, and wood quality. After 12 months of decomposition the proportion of lignin:carbohydrates varied significantly by inoculation treatment, with white rot having the only average proportional decrease in lignin:carbohydrates. Both soil $\mathrm{CO}_{2}$ efflux and DOC losses indicate that wood location is important. Carbon losses were greater from surface wood chips compared with buried wood chips, implying the importance of buried wood for total ecosystem carbon stabilization. Treatments associated with climate change 
also had an effect on the level of decomposition. DOC losses, soil water characteristics, and FTIR data demonstrate the importance of fungal community on the degree of decomposition and the resulting byproducts found throughout the soil. 


\section{Introduction}

Soils are the largest sinks of carbon in terrestrial ecosystems, containing about 15002000 Pg of carbon, or about two-thirds of the total terrestrial carbon pool (Grandy and Neff, 2008; Schlesinger, 1977). Forest soils hold $\sim 17 \%$ of all the total soil carbon (Amthor et al., 1998). Soil organic carbon (SOC) is important for ecosystem function as it supplies plants with nutrients, maintains soil structure, and helps control the exchange of $\mathrm{CO}_{2}$ with the atmosphere (Grandy and Neff, 2008).

The major contributors to SOC in forest soils are litter, woody debris, and roots (Rasse et al., 2005). Woody residues represent $30 \%$ of litter contributions, tending to accumulate in forest soils in early stages of decomposition (Cotrufo and Ineson, 2000; Kalbitz et al., 2006). Although wood makes up a large component of total forest biomass, it is not known how important it is to SOC stabilization and carbon losses as $\mathrm{CO}_{2}$ and dissolved organic carbon (DOC). Also, the composition of woody aboveground biomass affects belowground processes by altering the composition of SOC and soil nutrients as well as altering the accessibility to carbon for microbial activities in the soil (Sayer, 2006).

Losses of SOC, in the form of soil $\mathrm{CO}_{2}$ efflux and DOC, come from decomposition processes related to microbial activity. Microbial activity, particularly wood decomposing fungi, are influenced by climate and differences in carbon quality in the early stages of wood decomposition in forest soils (Schlesinger, 1977; Cotrufo and Ineson, 2000; Loya et al., 2003). In later stages of decomposition, physical and chemical interactions between carbon and the soil related to the accessibility of carbon have a greater influence over microbial decomposition rates (Von Lützow et al., 2006).

The IPCC (Intergovernmental Panel on Climate Change) predicts that climate change will include widespread increases in atmospheric temperatures and precipitation, and increases in atmospheric $\mathrm{CO}_{2}$ and $\mathrm{O}_{3}$ levels (IPCC, 2014). Although these changes have the potential to stimulate aboveground productivity, they also have the potential to increase carbon losses as a result of increased decomposition. The release of carbon in the form of soil $\mathrm{CO}_{2}$ efflux from forest soils could create a positive feedback with climate 
change, accelerating the process and possibly turning forest soils from carbon sinks into carbon sources.

\subsection{Objectives}

The goal of this project was to increase the understanding of the importance of wood to forest ecosystem soil carbon fluxes. Therefore, we measured the early pathways of wood decomposition by different fungal communities in interaction with soil texture, wood location, temperature, and wood quality. We analyzed the factors controlling the decomposition of wood-derived carbon (carbon losses) in temperate forest soils to increase the understanding of how these factors interact. We measured the movement of wood-derived carbon as soil as soil $\mathrm{CO}_{2}$ efflux and DOC.

\subsection{Fungal decomposition influences on SOC losses}

Fungi are among the largest players in the decomposition of wood in forested ecosystems. Hardwood forests contain almost double the fungal biomass and microbial enzyme activity than cultivated lands and pasture lands (Grandy et al., 2009). Certain fungal species specialize in breaking down specific components of woody residues. Therefore, different types of fungi are needed to completely decompose wood.

Two of the main groups of wood-decomposing fungi include brown rot and white rot fungi. Brown rot fungi are very common among forest wood and have the capacity to decompose cellulose, hemicellulose, and other simple carbon compounds (Boddy and Watkinson, 1995). They cannot, however, decompose lignin. Brown rot fungi only have the ability to modify lignin from its original molecular form through oxidation.

White rot fungi have the capacity to decompose all components of wood, including lignin and other complex carbon compounds (Boddy and Watkinson, 1995). White rot fungi have extracellular enzymes that are able to break down the lignocellulose complex that is formed when lignin creates a protective shield around cellulose (Baldrian and Valaskova, 2008). Once the lignin is removed, the cellulose can then be reached (Osono, 2007). 
There is competition between fungi during all stages of decomposition (Fukami et al., 2010). The only way for the fungi to obtain their carbon and nutrient requirements is to decompose organic matter. Certain nutrients are limiting and are not readily available in the forms used by fungi. Therefore, they must use large quantities of energy in order to create enzymes necessary for the breakdown of organic matter to obtain carbon and other nutrients. Fungal communities vary widely among substrates because they have different niches for carbon resources (Hanson et al., 2008). Fungi respond to carbon availability and occupy substrates accordingly. The carbon niches of wood-rotting fungi also influence the remaining residues found in the soil (Gilbertson, 1980). Not surprisingly, this explains why it is observed that the concentration of lignin increases in woody residues decomposed by brown rot fungi (Preston et al., 1998; Preston et al., 2006).

Fungi alter the composition of soil organic matter. Fungi relocate nutrients within the soil profile transporting them through their hyphae. They can draw nutrients down from the soil surface into deeper soil pools. Fungi can alter soil structure by breaking up aggregates in their quest for organic matter. Fungal hyphae can even break apart solid aggregates through penetration (Baldrian and Valaskova, 2008; Osono, 2007). Fungi also affect the isotopic composition of carbon throughout the soil (Hobbie et al., 2004; Santruckova et al., 2000).

Hypothesis 1: White rot fungi would produce larger wood-derived carbon losses from soil $\mathrm{CO}_{2}$ efflux and DOC than brown rot fungi, because brown rot fungi decompose fewer wood components than white rot fungi.

Brown rot fungi decompose cellulose and hemicellulose components of wood, leaving behind lignin, whereas white rot fungi decompose all components of wood (Boddy and Watkinson, 1995).

Hypothesis 2: After 12 months of decomposition, the proportion of lignin:carbohydrates will decrease in wood chips inoculated with white rot fungi and would increase in wood chips inoculated with brown rot fungi, resulting in a significantly lower proportion of lignin:carbohydrates. 


\subsection{Other factors influencing SOC losses}

\section{Soil Texture}

The texture of soil is an important determinant of the amount of SOC that can be stored in a soil. Carbon accumulates in soils with high clay contents through both physical and chemical mechanisms such as aggregation, interactions with mineral surfaces, and entrapment in soil pores (Von Lützow et al., 2006). The ability of soils to be protective is lowered in soils with larger particle sizes, like sandy soils (Kaiser and Guggenberger, 2003; Grandy and Neff, 2008). Finer textured soils, with higher clay contents, typically contain more organic matter than coarser textured soils.

Aggregation can alter decomposition rates as well as SOC structure (Grandy and Neff, 2008). Aggregation influences the accessibility of residues to microbial decomposition, which directly plays a role in the destabilization of carbon in soils. Physical protection capabilities of soil are lowered in soils with larger particle sizes due to greater pore space and less aggregation (Grandy and Neff, 2008).

Hypothesis 3: loamy textured soils will produce fewer wood-derived carbon losses than sandy textured soils because there will be a larger amount of carbon to clay bonds formed, which will physically protect carbon from decomposition. This will likely only be seen when wood has direct contact with mineral soil below the soil surface.

\section{Residue location}

Decomposition of SOC is influenced by the location of organic matter within the soil profile. Residues found belowground, like lignified roots, are typically more recalcitrant and have a longer residence time in soils than aboveground biomass (Rasse et al., 2005; Trumbore, 2009). Belowground residues have more soil to residue contact than aboveground residues, increasing the chemical association formed between organic matter and mineral surfaces at greater depths (Rasse et al., 2001). Therefore belowground residues often have a greater impact on soil organic matter than aboveground residues because less carbon is lost through $\mathrm{CO}_{2}$ efflux and DOC (Huang and Spohn, 2015). For 
example, in temperate forests more root carbon is found in soils than that of leaf, branch, or stem litter combined (Helgason et al., 2014). In fact, studies have shown that aboveground carbon inputs have little effect on SOC, especially in temperate forests (Leff et al., 2012).

Hypothesis 4: There would be greater wood-derived carbon losses from soil $\mathrm{CO}_{2}$ efflux when wood chips are located on the surface compared to buried wood chips.

Hypothesis 5: Wood-derived carbon losses found in the DOC fraction of soil water would be greater in plots with buried chips. The buried chips will have more direct contact with soil water and therefore have a greater chance of being leached throughout the soil.

\section{Wood quality}

Wood quality specifically refers to both the physical and chemical properties of wood. Quality tends to be important in the early stages of decomposition and can influence the rate at which wood is decomposed (Von Lützow et al., 2006). Wood residues with increased C: $\mathrm{N}$ ratio, lignin: $\mathrm{N}$ ratio, lignin:cellulose ratio, and/or high lignin content have been found to decompose more slowly in numerous studies (Melillo et al., 1982; Taylor et al., 1989).

\subsection{Impacts of Climate Change}

\section{Warmed temperatures}

Warmer atmospheric temperatures will create warmer temperatures and likely lower moisture content throughout the soil profile. Soil temperature and soil moisture are two of the main controls over variations in soil $\mathrm{CO}_{2}$ efflux rates (Chen et al., 2013; Leavitt et al., 2001). Evidence suggests that higher temperatures will result in more decomposition and higher soil $\mathrm{CO}_{2}$ efflux rates (Chen et al., 2013; Melillo et al., 2002; Kirschbaum, 1995). An increase in enzyme activity, including lignin-degrading activity, as well as an increase 
in microbial accessibility to carbon has been noticed alongside increased temperatures (Feng et al., 2008; Conant et al., 2011).

The abundance of microbial activity also increases in conjunction with increases in soil moisture such as after rainfall events (Jassal et al., 2004). If temperature increases do not dry out the soil beyond the capacity of soil microbial communities, climate change has the potential to increase decomposition increasing carbon inputs to the atmosphere.

Hypothesis 6: Wood-derived carbon losses from soil $\mathrm{CO}_{2}$ efflux and DOC would be greater from passive warming temperature treatments compared to ambient temperature treatments.

\section{Elevated $\mathrm{CO}_{2}$ and $\mathrm{O}_{3}$}

Increases in atmospheric $\mathrm{CO}_{2}$ could alter carbon pools within the soil. Elevated levels of $\mathrm{CO}_{2}$ typically increase the productivity of aboveground biomass, which could potentially put more carbon into the soil. However, increases in SOC would likely be negated by an increase in decomposition (Hoosebeek et al,. 2006; Zak et al., 1993; Huang and Spohn, 2015). Many studies have found that elevated $\mathrm{CO}_{2}$ does not directly vary the amount of carbon found in the soil (Leavitt et al., 2001; Niklaus and Falloon, 2006; Talhelm et al., 2009). However, productivity of microbes belowground could increase with elevated $\mathrm{CO}_{2}$ because of increased carbon inputs. This is known as a priming effect, where fungi are stimulated to decompose the abundance of carbon in the soil (Zak et al., 1993). Fungi utilize more carbon within the soil in the presence of increased carbon inputs (Janus et al., 2005; Zak et al., 1993). In many studies, decomposition has increased under elevated $\mathrm{CO}_{2}$. Higher $\mathrm{CO}_{2}$ concentrations increased microbial productivity and directly increased the abundance of fungi in soils, promoting ligninolytic enzyme activity, and subsequently decomposition rates, which reduced SOC storage (Niklaus and Falloon, 2006; Talhelm et al., 2009; Carney et al., 2007).

Unlike increases in atmospheric $\mathrm{CO}_{2}$, increases in atmospheric $\mathrm{O}_{3}$ have been found to decrease plant productivity (Dickson et al., 1998; Loya et al., 2003).It is possible that plant responses to elevated $\mathrm{CO}_{2}$ could counteract responses to elevated $\mathrm{O}_{3}$; however, 
other studies have not found the same result (Dickson et al., 1998). Elevated $\mathrm{O}_{3}$ has also been found to decrease microbial enzyme activities in the soil (Phillips et al., 2002).

Increases in atmospheric $\mathrm{CO}_{2}$ and $\mathrm{O}_{3}$ also have the potential to alter wood quality of plants growing aboveground, which will ultimately affect the quality of woody residues returned to the soil via woody aboveground biomass and roots. The extent to which wood quality will be altered by increases in $\mathrm{CO}_{2}$ and $\mathrm{O}_{3}$ is unclear and studies have shown mixed results. Some studies demonstrated higher C:N and lignin: $\mathrm{N}$ ratios, while others found decreases in lignin and, instead, increases in nonstructural carbohydrates, soluble sugars, and starches (Cotrufo and Ineson, 2000; Blaschke et al., 2002; Kaakinen et al., 2004; Niklaus and Falloon, 2006). There are also reports of no chemical composition changes in wood (Atwell et al., 2003; Runion et al., 1999). It appears that each woody plant species reacts differently to $\mathrm{CO}_{2}$ and $\mathrm{O}_{3}$ increases and results vary from study to study. Regardless of chemical differences found within woody tissues, differences in decomposition rates have been small and not significant (Cotrufo and Ineson, 2000; Ebenyenle, 2012; Niklaus and Falloon, 2006).

Hypothesis 7: There would be no difference in wood-derived carbon losses between ambient and elevated $\mathrm{CO}_{2}$ wood quality treatments but larger carbon losses from the elevated $\mathrm{CO}_{2}+\mathrm{O}_{3}$ wood quality treatments. The initial laboratory wood mass loss data from one type of aspen clone showed that the ambient wood quality and elevated $\mathrm{CO}_{2}$ wood quality treatments had similar total mass loss (Fig. 1). However, elevated $\mathrm{CO}_{2}+\mathrm{O}_{3}$ wood quality treatments showed greater initial mass loss based on the same wood mass loss data. 


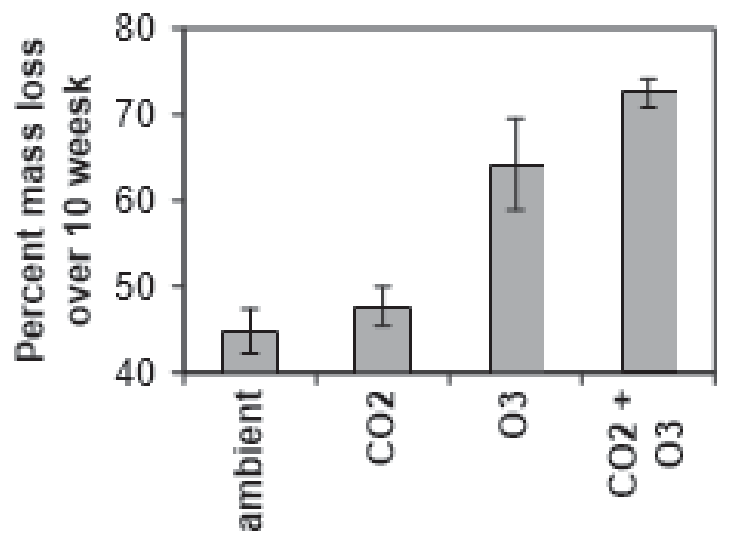

Fig. 1. Changes in decomposition rates in four different aspen FACE treatments inoculated with white rot fungus 


\section{Methods}

\subsection{Experimental Design}

All wood used in the decomposition study was aspen wood (Populus tremuloides Michx) and came from the Aspen FACE (Free Air Carbon dioxide Enrichment; Rhinelander, WI) experimental trees that were harvested in 2009 and stored until use for this project. The Aspen FACE experimental trees were given the following three fumigation treatments during their growth from 1997 to 2009, representing the wood quality treatment: elevated $\mathrm{CO}_{2}$, elevated $\mathrm{CO}_{2}+\mathrm{O}_{3}$, and ambient atmospheric conditions. Treatments with elevated $\mathrm{CO}_{2}$ and elevated $\mathrm{CO}_{2}+\mathrm{O}_{3}$ were fumigated with 560 ppm $\mathrm{CO}_{2}$ and $1.5 \mathrm{x}$ ambient $\mathrm{O}_{3}$.

The Aspen FACE wood grown with ambient atmospheric conditions had an average $\delta^{13} \mathrm{C}$ signature of $-27 \%$, very similar to the average $\delta^{13} \mathrm{C}$ signature of soil found at all of the research sites (-26.8\%; Table 1). However, the Aspen FACE wood fumigated with elevated $\mathrm{CO}_{2}$ and elevated $\mathrm{CO}_{2}+\mathrm{O}_{3}$ had an average $\delta^{13} \mathrm{C}$ signature of $-39 \%$, due to the incorporation of a pure fossil fuel source of $\mathrm{CO}_{2}$ (Fig. 2). This $>12 \%$ depletion in ${ }^{13} \mathrm{C}$ in the elevated $\mathrm{CO}_{2}$ and elevated $\mathrm{CO}_{2}+\mathrm{O}_{3}$ aspen wood treatments provided the basis for measuring the loss of wood-derived $\mathrm{C}$ from soil as $\mathrm{CO}_{2}$ efflux and in soil water as DOC through the early stages of decomposition.

In 2011, the aspen tree stems were chipped so that decomposition could be monitored on a quicker time scale and the chips could be more evenly ramified with specific fungal inoculations. After chipping, the chips were heat treated at $80^{\circ} \mathrm{C}$ for sterilization with respect to the fungi populations and inoculated with wood decaying fungi. There were three inoculation treatments: pure colonies of white rot fungi (Bjerkandera adusta), pure colonies of brown rot fungi (Gloeophyllum saeparium), and natural rot, a suite of microbial species endemic to the aspen wood at the time of chipping. The white and brown rot fungi were chosen for their abundance in forested ecosystems and their tendency to decompose differing wood components. Specifically, brown rot fungi decompose cellulose, hemicellulose, and other simple carbon components, but do not decompose lignin. White rot fungi decompose all wood components, lignin included 
(Boddy and Watkinson, 1995). For the pure species cultures, fungi were grown in 100 $\mathrm{mm}$ petri plates on $2 \%$ malt agar, then transferred to each jar of primary inoculum chips (aspen wood chips from the ambient atmosphere FACE treatment). For the natural rot treatments, the ambient atmosphere FACE wood chips were placed directly into jars and treated the same as the pure inoculum. Jars were incubated at $25-27^{\circ} \mathrm{C}$ for six weeks to allow thorough colonization of the wood chips. Once the inoculum was ready, approximately $14 \mathrm{~kg}$ (dry weight) batches of wood chips were inoculated with one of the three cultures of fungal communities. Two liters of inoculum was added and mixed into each $14 \mathrm{~kg}$ batch of wood chips in $88 \mathrm{~L}$ plastic totes to be used for each plot. After inoculation, the wood chips were incubated in $\sim 1 \mathrm{~kg}$ batches for 3 months at $\sim 18^{\circ} \mathrm{C}$.

After inoculation and incubation, the wood chips were deployed across the six research sites located in the Upper Peninsula of Michigan (Fig. 3) in the late summer, 2012. Each site $\left(\sim 1600 \mathrm{~m}^{2}\right)$ consisted of aspen clear-cuts that were cut in the summer, 2012. The research sites were specifically selected for their soil texture. Three of the sites are found on coarse textured, sandy soils and the other three sites are found on finer textured soils classified as loams (Table 1). A total of 168 individual research plots $\left(1 \mathrm{~m}^{2}\right)$ were created across the six sites. Approximately $14 \mathrm{~kg}$ of chips were used for each $1 \mathrm{~m}^{2}$ research plot. Wood chips were either placed on the surface of the plots or buried $15 \mathrm{~cm}$ below the soil surface to represent lignified roots. Control plots without wood added ("no wood" controls) were created at each research site. For the buried "no wood" control treatment, the soil was excavated to $15 \mathrm{~cm}$. Instead of adding wood chips, like the buried chip treatments, the soil was returned to the plot without wood. For the surface "no wood" control treatment, the plots are the same $1 \mathrm{~m}^{2}$ in area with no wood added to the surface. All research plots were randomly distributed around the cleared site, leaving at least $1 \mathrm{~m}$ between plots and a $10 \mathrm{~m}^{2}$ buffer around the edge of the cleared area.

A warmed temperature treatment was also established on a subset of 48 plots (Table 2). Plots were exposed to either ambient temperatures or to passive warming using opentop chambers (OTCs). The OTCs were created from Sun-Lite ${ }^{\circledR}$ HP fiberglass glazing panels constructed into a cone shape. The base diameter was $1 \mathrm{~m}$ with $60^{\circ}$ sloping sides. The OTCs were intended to raise plot temperatures $\sim 2^{\circ} \mathrm{C}$ (Marion et al., 1997). For 
warmed no wood control treatments, an OTC was added to the control plots. Soil temperature was monitored in a subsample of plots with and without OTCs (50 total) with Maxim Integrated i-button data loggers. Temperature readings were taken every hour from three different soil depths (soil surface, $7.5 \mathrm{~cm}$ below surface, and $15 \mathrm{~cm}$ below surface). This data was able to be downloaded to a computer in the field.

\subsection{Laboratory Incubations}

Laboratory incubations began in March 2013 to look at the effect of the different wood quality and fungal community treatments on $\mathrm{CO}_{2}$ efflux rates in a controlled setting. Laboratory incubations were also used to determine the pure $\delta^{13} \mathrm{C}$ signature of the wood and the pure $\delta^{13} \mathrm{C}$ signature of wood respired $\mathrm{CO}_{2}$ during decomposition. All wood chips for the laboratory incubations were stored in jars in a humidity-controlled setting at $26 \pm 3^{\circ} \mathrm{C}$ and $80 \pm 10 \%$ relative humidity. For determining the $\delta^{13} \mathrm{C}$ signature of the wood, the wood chips were sampled and ground up with first a Wiley mill followed by a ball mill at 6 different times over the course of a year. The wood chips were then analyzed for the $\delta^{13} \mathrm{C}$ signature using a Costech Elemental Combustion system 4010 connected to a ThermoFinnigan Delta ${ }^{\text {plus }}$ Continuous Flow Stable Isotope Ratio Mass Spectrometer (Costech Analytical Technologies Inc., Valencia, CA, USA; Thermo Fisher Scientific Inc., Waltham, MA, USA). IAEA, USGS, and NIST certified isotopic standards were run at the beginning of each analysis. One certified standard was also run at the end of the analysis to check for stability of the calibration. These standards are recognized internationally. Values were reported on the VPDB scale for $\delta^{13} \mathrm{C}$. An internal standard was usually run every 10 samples. The precision of the certified isotopic standards are typically 0.2 to $0.5 \%$. To determine the $\delta^{13} \mathrm{C}$ signature of the pure wood respired $\mathrm{CO}_{2}$,the jars were flushed with $\mathrm{CO}_{2}$-free air via soda lime for 5 minutes. The wood chips were then left to respire. The $\mathrm{CO}_{2}$ gas samples were extracted from the jars through septa at 5 pre-determined time intervals (i.e., 0, 30, 60, 90, 120 minutes) over the course of 2 hours. Laboratory incubations occurred at 6 different time periods over a one year time frame. The samples were analyzed for $\mathrm{CO}_{2}$ concentrations (ppm) with a gas chromatograph (Agilent 6850 Gas Chromatograph with Thermoconductivity detector 
Santa Clara, CA, USA) and for $\delta^{13} \mathrm{C}$ values using a GasBenchII connected to a ThermoFinnigan Delta ${ }^{\text {plus }}$ Continuous Flow Stable Isotope Ratio Mass Spectrometer (Thermo Fisher Scientific Inc., Waltham, MA, USA; Table 3). The gas chromatograph was calibrated with a $1500 \mathrm{ppm} \mathrm{CO}$ gas standard curve. The inverse of the $\mathrm{CO}_{2}$ concentrations were plotted on an $\mathrm{x}$-axis against the associated $\delta^{13} \mathrm{C}$ values on a y-axis to create Keeling plots (Fig. 4). The y-intercept represents the true isotopic signature of the $\mathrm{CO}_{2}$ respired from the wood chips. By using a Keeling plot, a more accurate isotope signature can be determined without the contamination of atmospheric $\mathrm{CO}_{2}$.

\subsection{Soil $\mathrm{CO}_{2}$ Efflux}

Soil surface $\mathrm{CO}_{2}$ efflux was measured on four occasions per growing seasons in 2013 and 2014. Measurements were taken from a subsample of the research plots (Table 4), using a PP Systems EGM-2 or EGM-4 infrared gas analyzer (IRGA) with an attached closed system chamber (SRC-1; Amesbury, MA, USA). There were a total of 6 experimental treatments and 2 control plots measured at each sand textured research site. At each loam textured research site, there were a total of 22 experimental treatments and 4 control plots measured. Each plot was equipped with 3 custom fit PVC collars (approximately $10 \mathrm{~cm}$ in diameter, inserted approximately $2 \mathrm{~cm}$ into plot surface). Soil $\mathrm{CO}_{2}$ efflux measurements were made by attaching the IRGA and chamber to each of the 3 collars. The 3 efflux measurements were then averaged to ensure a representative soil $\mathrm{CO}_{2}$ efflux rate for the plot.

Similar to the laboratory incubations, Keeling plots were also used to estimate the $\delta^{13} \mathrm{C}$ signature of the soil $\mathrm{CO}_{2}$ efflux. A connector line with septa was put into the input gas line of the IRGA. The IRGA and chamber was attached to a PVC collar and left to measure the $\mathrm{CO}_{2}$ concentration for 15 minutes, allowing the $\mathrm{CO}_{2}$ to accumulate in the chamber over this time period. Gas samples were extracted from the septa with a syringe and injected into a He flushed IRMS vial. Samples were drawn at 5 minute increments (i.e., 0, 5, 10, and 15 minutes). The associated $\mathrm{CO}_{2}$ concentration reading from the IRGA was recorded simultaneously. The $\delta^{13} \mathrm{C}$ signatures of each soil $\mathrm{CO}_{2}$ efflux gas sample were determined using a GasBench II connected to a ThermoFinnigan Delta ${ }^{\text {plus }}$ 
Continuous Flow-Stable Isotope Ratio Mass Spectrometer (Thermo Fisher Scientific Inc., Waltham, MA, USA). These $\delta^{13} \mathrm{C}$ values were then paired with the inverses of $\mathrm{CO}_{2}$ concentration values, recorded from the IRGA in the field, to create Keeling plots. The yintercepts from the keeling plots represent the true isotopic signature of the soil $\mathrm{CO}_{2}$ efflux from research plots without atmospheric contamination. Keeling plots were preformed once during peak growing season for two years, 2013 and 2014.

The pure wood $\delta^{13} \mathrm{CO}_{2}$ values from the laboratory incubations along with the $\delta^{13} \mathrm{C}$ values of the soil $\mathrm{CO}_{2}$ efflux were used to determine the percentage of wood-derived soil $\mathrm{CO}_{2}$ efflux (\%wood of CO2) by using a 2-endpoint mixing model (Del Gado et al., 2003):

$\%_{\text {wood of } \mathrm{CO} 2}=\left(\left(\delta^{13} \mathrm{C}_{\text {soil efflux }}-\delta^{13} \mathrm{C}\right.\right.$ "no wood" control CO2 $) /\left(\delta^{13} \mathrm{C}_{\text {pure wood } \mathrm{CO} 2}-\delta 13 \mathrm{C}\right.$ "no wood" control CO2 $\left.)\right) \times 100$, (Eqn.1)

where $\delta^{13} \mathrm{C}$ soil efflux is the $\delta^{13} \mathrm{C}$ value of the soil $\mathrm{CO}_{2}$ efflux from each plot, $\delta^{13} \mathrm{C}_{\text {no wood }}$ control is the $\delta^{13} \mathrm{C}$ of soil $\mathrm{CO}_{2}$ efflux from no wood control plots corresponding to the same treatments as the treatment plots, and the $\delta^{13} \mathrm{C}_{\text {pure wood }}$ is the $\delta^{13} \mathrm{C}$ of pure wood $\mathrm{CO}_{2}$ efflux determined during laboratory incubations (Table 3).

\subsection{Soil Water Chemistry}

In order to analyze soil water chemistry and initial carbon losses through DOC, resulting from decomposition, lysimeters were included in a subset of 40 plots across two loam textured sites (Table 5). In the spring of 2013, $30 \mathrm{~cm}$ lysimeters were inserted near the center of the plots (Soil Moisture Corp., Goleta, CA, USA). A vacuum was created within the lysimeters to draw up soil water through a porous cup. Any available soil water was extracted twice during the growing season of 2013 and 2014. Soil water samples were filtered through a 0.45 micron filter prior to analysis of DOC, soil water absorbance ( $\lambda=254,365,465$, and $665 \mathrm{~nm}$ ), and total phenolics (hydrolyzed aromatic compounds relative to tannic acid standard; Hach corporation TanniVer reagent). The remainder of the water samples were then freeze-dried and analyzed for the $\delta^{13} \mathrm{C}$ signature of DOC. Soil water absorbance was measured using a Spectra Max M2 multimode microplate reader (Molecular Devices Corporation, Sunnyvale, CA, USA). 
DOC aromaticity was determined by dividing $\lambda=254 \mathrm{~nm}$ by total DOC to calculate specific ultraviolet absorbance at $254 \mathrm{~nm}\left(\mathrm{SUVA}_{254}\right)$. The ratio of $\lambda=254 \mathrm{~nm}$ to $\lambda=365$ $\mathrm{nm}$ was used as an indicator of molecular size of DOC and the ratio of $\lambda=465 \mathrm{~nm}$ to $\lambda=$ $665 \mathrm{~nm}$ was used as indicator of humification of DOC (Hribljan et al., 2014).

The pure wood $\delta^{13} \mathrm{C}$ values from the laboratory incubations along with the $\delta^{13} \mathrm{C}$ values of the freeze-dried DOC were used to determine the percentage of total DOC

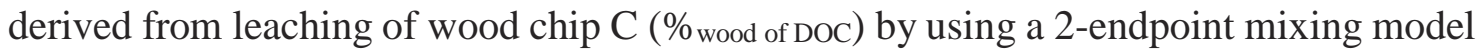
(Del Gado et al., 2003):

$\%_{\text {wood of DOC }}=\left(\left(\delta^{13} \mathrm{C}_{\text {DOC }}-\delta^{13} \mathrm{C}_{\text {DOC "no wood" control DOC }}\right) /\left(\delta^{13} \mathrm{C}_{\text {pure wood }}-\delta^{13} \mathrm{C}_{\text {DOC "no wood" control DOC }}\right)\right) \mathrm{x} 100$, (eqn.

2)

where $\delta^{13} \mathrm{C}_{\mathrm{DOC}}$ is the $\delta^{13} \mathrm{C}$ value of the DOC from each plot, $\delta^{13} \mathrm{C}_{\mathrm{DOC}}$ of no wood control is the $\delta^{13} \mathrm{C}$ of DOC from no wood control plots corresponding to the same treatments as the treatment plots, and the $\delta^{13} \mathrm{C}_{\text {pure wood }}$ is the $\delta^{13} \mathrm{C}$ of pure wood determined during laboratory incubations (Table 3).

\subsection{FTIR Analysis}

FTIR (Fourier Transform Infrared Spectrometry) analysis was used to determine if there were temporal changes in wood chip chemistry resulting from wood quality and fungal decomposer interactions during decomposition. The analysis used infrared light and adsorption wavelengths to identify specific chemical compounds found in the wood chips. In March 2013, chipped wood samples used for FTIR were stored in separate jars

alongside the wood chips used for the laboratory incubations described above. The wood chips that were analyzed represented a full factorial design of the 3 wood quality treatments (i.e., ambient, elevated $\mathrm{CO}_{2}$, and elevated $\mathrm{CO}_{2}+\mathrm{O}_{3}$ ) and the 3 fungal inoculation treatments (i.e., brown, white, and natural rots) for a total of 9 treatments. The wood chip samples were oven dried at $65^{\circ} \mathrm{C}$ to constant mass and then they were ground first with a Wiley mill and then a ball mill. A total of 27 wood samples were analyzed with FTIR analysis. Of the 27 samples, 9 samples were the initial conditions of the wood 
at the onset of the incubation (March 2013), 9 samples were the treatments 4 months later (July 2013), and 9 samples were the treatments one year later (June 2014).

The FTIR analysis wavelength absorbance output was used to create the proportion of lignin to other carbohydrates. These proportions were compared across the three incubation times (i.e., time 0, 4 months, 1 year). Absorbance intensities for lignin bands were compared against carbohydrate bands to determine if the relative proportion of lignin:carbohydrates decreased or increased as decomposition progressed, following the methods of Pandey et al., 2003. The lignin reference peak used was $1505 \mathrm{~cm}^{-1}$. While other peaks also account for lignin, this reference peak arises only from the aromatic skeletal vibration $(\mathrm{C}=\mathrm{C})$ in lignin, with no contributions from carbohydrates. Four different carbohydrate reference peaks were used: $1738 \mathrm{~cm}^{-1}$ representing the unconjugated $\mathrm{C}=\mathrm{O}$ in xylans (specifically attributed to hemicellulose), $1375 \mathrm{~cm}^{-1}$ representing the $\mathrm{C}-\mathrm{H}$ deformation in cellulose and hemicellulose, $1158 \mathrm{~cm}^{-1}$ representing the C-O-C vibration in cellulose and hemicellulose, and $898 \mathrm{~cm}^{-1}$ representing the C-H deformation in cellulose. These carbohydrate reference peaks were chosen because they arise purely from carbohydrates, with no contributions from lignin. Decreases in these ratios throughout decomposition show evidence for lignin degradation.

Proportions were also compared for the deformation, or demethylation, of lignin. While brown rot fungi cannot decompose lignin, they can alter the chemical structure of lignin by removing methoxy groups, which would affect the chemical absorbance intensities in the FTIR output. Peaks representing the C-H deformation of lignin, 1462 $\mathrm{cm}^{-1}$ and $1425 \mathrm{~cm}^{-1}$, were compared against the reference lignin peak, $1505 \mathrm{~cm}^{-1}$. Decreases in these proportions throughout decomposition show evidence for the demethylation of lignin.

\subsection{Statistical Analyses}

A general linear mixed-effects model with repeated measures was used to determine which factors had an effect on average total soil $\mathrm{CO}_{2}$ efflux, wood-derived soil $\mathrm{CO}_{2}$ efflux, and the average percentage of wood-derived soil $\mathrm{CO}_{2}$ efflux using SAS 9.4 (SAS Institute Inc., Cary, NC, USA). The same model was used to determine which factors had 
an effect on average total soil water DOC, wood-derived portion of total DOC, and the average percentage of wood-derived DOC. Plot level replications were represented as random variables. The repeated measures component was represented by the date of sample and was used to ensure that the change in soil $\mathrm{CO}_{2}$ efflux and soil water DOC for each plot through time was accounted for and analyzed independently. Each treatment (i.e., soil texture, wood chip location, temperature, wood quality, and fungal inoculation) was considered a fixed categorical predictor variable and was given a fixed value.

Model assumptions were checked to make sure that each response variable was normal with constant variance. A log transformation was used on the average total soil $\mathrm{CO}_{2}$ efflux, the wood-derived soil $\mathrm{CO}_{2}$ efflux, and average tannin content. The average percentage of wood-derived soil $\mathrm{CO}_{2}$ efflux, the wood-derived DOC, average SUVA254, and the ratios of $\lambda=254 \mathrm{~nm}$ to $\lambda=365 \mathrm{~nm}$ and $\lambda=465 \mathrm{~nm}$ to $\lambda=665 \mathrm{~nm}$ needed no transformation. An inverse transformation was used on the average total soil water DOC and average tannin. A square root transformation was used on the average percentage of wood-derived DOC. Tukeys multiple comparisons of means post hoc tests were used to further analyze differences within treatments. An analysis of covariance was also performed, with total soil $\mathrm{CO}_{2}$ efflux used as the dependent variable and total DOC and fungal inoculation used as the dependent variables. The significant p-value cut-off was 0.05 . 


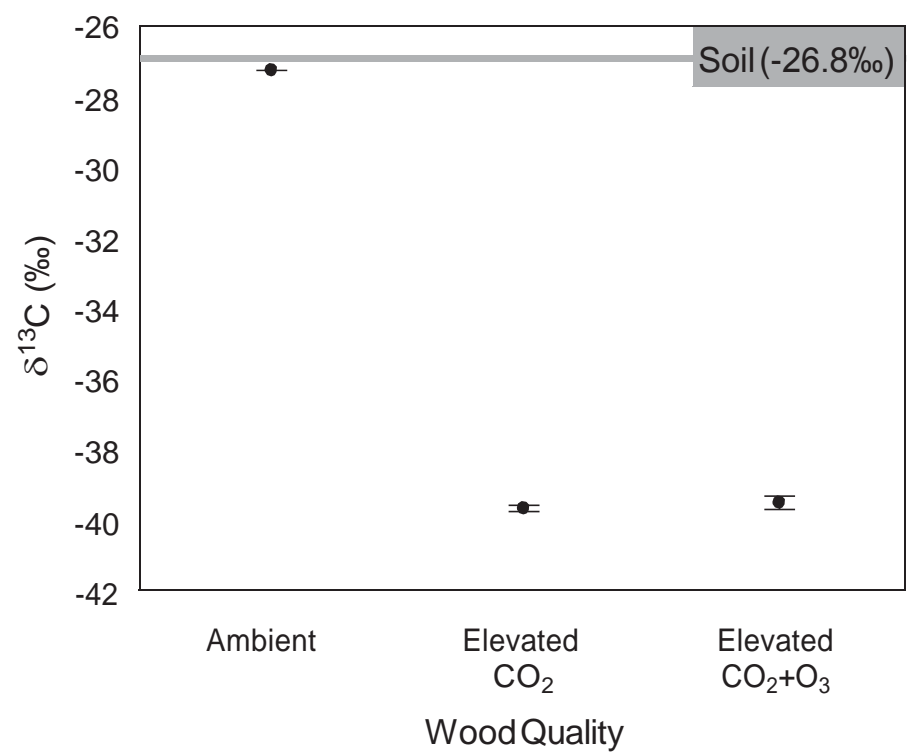

Fig. 2. $\delta^{13} \mathrm{C}$ values of wood quality treatments from FACE site and soil for the 6 research sites 


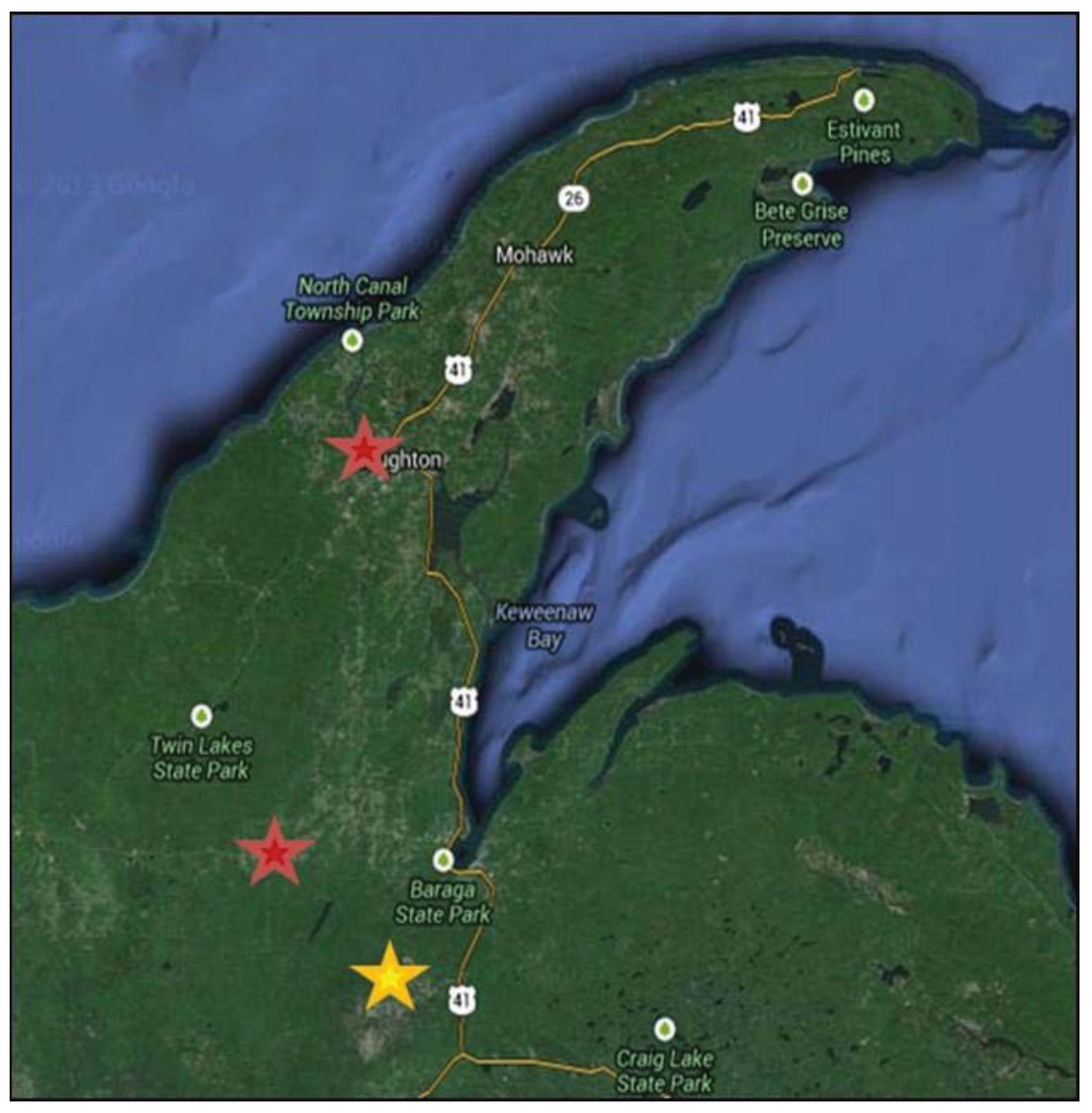

Fig. 3. Map of research site locations. Red indicates loam textured sites and yellow indicated sandy textured sites. 


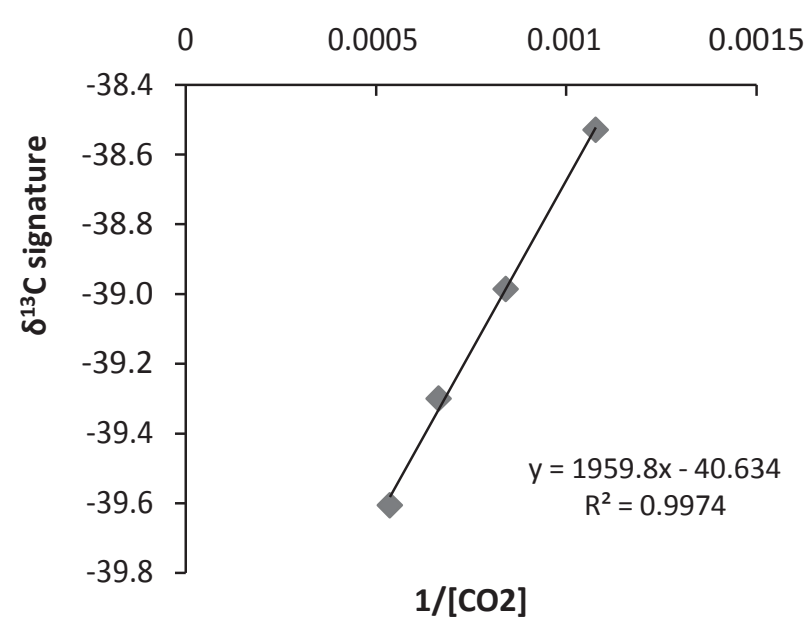

Fig. 4. An example keeling plot graph from the laboratory incubations where the $y$-intercept (-40.634) represents the true isotopic signature of respired $\mathrm{CO}_{2}$ 


\section{Table 1}

Site descriptions. Sites 1-3 were denoted as sands and sites 4-6 were denoted as loams. Average $\delta^{13} \mathrm{C}$ of soil, bulk density, and average temperature reported \pm standard errors.

\begin{tabular}{|c|c|c|c|c|c|c|c|}
\hline site & soil depth & $\begin{array}{l}\text { average } \\
\delta^{13} \mathrm{C}(\% \circ)\end{array}$ & $\begin{array}{c}\text { bulk density } \\
\left(\mathrm{g} / \mathrm{cm}^{3}\right)\end{array}$ & $\%$ sand & $\%$ silt & $\%$ clay & $\begin{array}{c}\text { average } \\
\text { temp. }\left({ }^{\circ} \mathrm{C}\right)\end{array}$ \\
\hline sand 1 & \multirow{6}{*}{$0-15 \mathrm{~cm}$} & $-27.2 \pm 0.1$ & $1.18 \pm 0.07$ & 83.8 & 13.1 & 3.1 & $17.79 \pm 1.93$ \\
\hline sand 2 & & $-26.6 \pm 0.0$ & $1.16 \pm 0.02$ & 75.8 & 22.1 & 2.1 & $16.87 \pm 0.82$ \\
\hline sand 3 & & $-27.4 \pm 0.1$ & $1.23 \pm 0.04$ & 82.9 & 17.0 & 0.1 & $16.15 \pm 0.93$ \\
\hline loam 1 & & $-27.1 \pm 0.1$ & $0.90 \pm 0.07$ & 34.8 & 47.1 & 18.1 & $18.90 \pm 0.64$ \\
\hline loam 2 & & $-27.2 \pm 0.0$ & $0.95 \pm 0.08$ & 68.8 & 24.1 & 7.1 & $18.01 \pm 0.50$ \\
\hline loam 3 & & $-27.2 \pm 0.0$ & $0.93 \pm 0.05$ & 71.8 & 23.0 & 5.2 & $16.40 \pm 0.43$ \\
\hline sand 1 & \multirow{6}{*}{$15-30 \mathrm{~cm}$} & $-25.9 \pm 0.0$ & $1.07 \pm 0.08$ & 88.9 & 9.0 & 2.1 & $13.97 \pm 1.36$ \\
\hline sand 2 & & $-25.7 \pm 0.0$ & $1.14 \pm 0.06$ & 78.8 & 19.2 & 2.0 & $14.89 \pm 0.62$ \\
\hline sand 3 & & $-26.6 \pm 0.1$ & $1.06 \pm 0.08$ & 88.9 & 10.0 & 1.1 & $14.21 \pm 0.77$ \\
\hline loam 1 & & $-25.7 \pm 0.1$ & $1.32 \pm 0.15$ & 38.9 & 35.1 & 26.0 & $15.66 \pm 0.48$ \\
\hline Ioam 2 & & $-27.3 \pm 0.1$ & $1.08 \pm 0.08$ & 74.8 & 22.1 & 3.1 & $15.42 \pm 0.43$ \\
\hline loam 3 & & $-26.8 \pm 0.0$ & $1.21 \pm 0.12$ & 84.8 & 13.0 & 2.2 & $14.46 \pm 0.42$ \\
\hline
\end{tabular}


Table 2

Research design and distribution of passive warming temperature treatment plots

\begin{tabular}{|c|c|c|c|c|c|}
\hline \multirow{3}{*}{ Treatment } & \multicolumn{4}{|c|}{ Passive Warming Temperature } & \multirow{2}{*}{ Plot Totals } \\
\hline & \multicolumn{2}{|c|}{ Loam } & \multicolumn{2}{|c|}{ Sand } & \\
\hline & Warmed & No wood control & Warmed & No wood control & \\
\hline $\begin{array}{l}\text { Wood } \\
\text { location }\end{array}$ & $\begin{array}{l}2 \text { (buried, } \\
\text { surface) }\end{array}$ & 2 (buried, surface) & $\begin{array}{l}2 \text { (buried, } \\
\text { surface) }\end{array}$ & $\mathrm{N} / \mathrm{A}$ & \\
\hline Inoculation & $\begin{array}{c}3 \text { (brown, } \\
\text { white, natural } \\
\text { rot) }\end{array}$ & $\mathrm{N} / \mathrm{A}$ & $\begin{array}{c}3 \text { (brown, } \\
\text { white, natural } \\
\text { rot) }\end{array}$ & N/A & \\
\hline $\begin{array}{l}\text { Wood } \\
\text { Quality }\end{array}$ & $\begin{array}{c}2 \text { (ambient, } \\
\left.+\mathrm{CO}_{2}\right)\end{array}$ & $\mathrm{N} / \mathrm{A}$ & $\begin{array}{c}2 \text { (ambient, } \\
\left.+\mathrm{CO}_{2}\right)\end{array}$ & $\mathrm{N} / \mathrm{A}$ & \\
\hline $\begin{array}{c}\text { Plot } \\
\text { Subtotal }\end{array}$ & 12 plots & 2 plots & 2 plots & N/A & \\
\hline Replication & 3 sites & 3 sites & 3 sites & 3 sites & \\
\hline Plot Total & 36 plots & 6 plots & 6 plots & N/A & 48 plots \\
\hline
\end{tabular}




\section{Table 3}

Average pure wood $\delta^{13} \mathrm{C}$ and pure wood $\delta^{13} \mathrm{CO}_{2}$ values \pm standard errors from laboratory incubations taken from six sampling dates over one year.

\begin{tabular}{|l|c|c|}
\hline Wood quality/inoculation treatment & Pure wood $\boldsymbol{~}^{13} \mathbf{C}$ value & Pure wood $\boldsymbol{~}^{13} \mathrm{CO}_{2}$ value \\
\hline$+\mathrm{CO} 2 /$ brown rot & $-38.05 \pm 0.38$ & $-38.94 \pm 0.53$ \\
\hline$+\mathrm{CO} 2 /$ white rot & $-38.16 \pm 0.21$ & $-41.09 \pm 0.38$ \\
\hline$+\mathrm{CO} 2 /$ natural rot & $-38.71 \pm 0.35$ & $-38.95 \pm 0.82$ \\
\hline$+\mathrm{CO}+\mathbf{O} 3 /$ brown rot & $-39.02 \pm 0.30$ & $-42.20 \pm 1.31$ \\
\hline$+\mathrm{CO}+\mathbf{O} 3 /$ white rot & $-38.42 \pm 0.32$ & $-41.95 \pm 1.34$ \\
\hline$+\mathrm{CO}+\mathbf{O} 3 /$ natural rot & $-38.99 \pm 0.25$ & $-40.25 \pm 1.90$ \\
\hline
\end{tabular}


Table 4

Research design and distribution of plots measured for soil surface $\mathrm{CO}_{2}$ efflux and $\delta^{13} \mathrm{CO}_{2}$.

\begin{tabular}{|c|c|c|c|c|c|}
\hline \multirow{3}{*}{ Treatments } & \multicolumn{4}{|c|}{ Soil Surface $\mathrm{CO}_{2}$ Efflux Sampling } & \multirow{2}{*}{ Plot Totals } \\
\hline & \multicolumn{2}{|c|}{ Loam } & \multicolumn{2}{|c|}{ Sand } & \\
\hline & Experimental & No Wood Control & Experimental & No Wood Control & \\
\hline Wood Location & 2 (surface, buried) & 2 (surface, buried) & 2 (surface, buried) & 2 (surface, buried) & \\
\hline Inoculation & $\begin{array}{c}3 \text { (white, brown, } \\
\text { natural rot) }\end{array}$ & N/A & $\begin{array}{c}3 \text { (white, brown, } \\
\text { natural rot) }\end{array}$ & $\mathrm{N} / \mathrm{A}$ & \\
\hline Wood Quality & $\begin{array}{c}3 \text { (ambient, }+\mathrm{CO}_{2} \\
\left.+\mathrm{CO}_{2}+\mathrm{O}_{3}\right) *\end{array}$ & N/A & $1\left(+\mathrm{CO}_{2}\right)$ & N/A & \\
\hline Temperature & $\begin{array}{l}2 \text { (ambient, } \\
\text { elevated) ** }\end{array}$ & $\begin{array}{l}2 \text { (ambient, } \\
\text { elevated) }\end{array}$ & $\mathrm{N} / \mathrm{A}$ & N/A & \\
\hline Plot Subtotal & 22 plots & 4 plots & 6 plots & 2 plots & \\
\hline Replication & 3 & 3 & 3 & 3 & \\
\hline Plot Total & 66 plots & 12 plots & 18 plots & 6 plots & 102 \\
\hline \multicolumn{6}{|c|}{ *In fine texture soils, only natural rot inoculations were measured for plots with ambient wood quality } \\
\hline \multicolumn{6}{|c|}{ **In fine texture soils, only ambient temperatures were measured for plots with $+\mathrm{CO}_{2}+\mathrm{O}_{3}$ wood quality } \\
\hline
\end{tabular}


Table 5

Research design and distribution of plots equipped with lysimeters for soil water sampling

\begin{tabular}{|c|c|c|c|}
\hline \multirow{3}{*}{ Treatments } & \multicolumn{2}{|c|}{ Soil Water Sampling } & Plot Totals \\
\hline & \multicolumn{2}{|c|}{ Loam Texture } & \\
\hline & Experimental & No Wood Control & \\
\hline Wood Location & 2 (surface, buried) & 2 (surface, buried) & \\
\hline Inoculation & $\begin{array}{c}3 \text { (brown, white, } \\
\text { natural rot) }\end{array}$ & N/A & \\
\hline Wood Quality & 2 (ambient, $+\mathrm{CO}_{2}$ ) & N/A & \\
\hline Temperature & $\begin{array}{l}2 \text { (ambient, } \\
\text { elevated) }\end{array}$ & $\begin{array}{l}2 \text { (ambient, } \\
\text { elevated) }\end{array}$ & \\
\hline Plot Subtotal & 16 Plots & 4 Plots & \\
\hline Replication & 2 sites & 2 sites & \\
\hline Plot Total & 32 Plots & 8 Plots & 40 Plots \\
\hline
\end{tabular}




\section{Results}

\subsection{Soil $\mathrm{CO}_{2}$ Efflux}

The average total soil $\mathrm{CO}_{2}$ efflux rates are an average of all efflux measurements across 2 growing seasons. The percentage of wood-derived soil $\mathrm{CO}_{2}$ efflux (Eqn. 1) is an indication of how much wood is being decomposed independent of total soil $\mathrm{CO}_{2}$ efflux rates. The wood-derived portion of soil $\mathrm{CO}_{2}$ efflux rates was created by multiplying soil $\mathrm{CO}_{2}$ efflux rates by the percentage of wood-derived soil $\mathrm{CO}_{2}$ efflux for a given measurement period. All averages are expressed \pm 1 standard error.

The soil $\mathrm{CO}_{2}$ efflux rates ranged, on average, from seasonal lows of 0.28 to1.60 $\mathrm{g}$ $\mathrm{CO}_{2} \mathrm{~m}^{-2} \mathrm{~h}^{-1}$ in the spring and fall to highs of 1.77 to $2.92 \mathrm{~g} \mathrm{CO}_{2} \mathrm{~m}^{-2} \mathrm{~h}^{-1}$ in the peak growing season of 2013 and 2014, with a maximum of 9.21 and a minimum of $0.06 \mathrm{~g}$ $\mathrm{CO}_{2} \mathrm{~m}^{-2} \mathrm{~h}^{-1}$. The wood-derived portion of the total soil $\mathrm{CO}_{2}$ efflux was about half the total efflux rate, ranging, on average, from 0.13 to $1.77 \mathrm{~g} \mathrm{CO}_{2} \mathrm{~m}^{-2} \mathrm{~h}^{-1}$. The average total soil $\mathrm{CO}_{2}$ efflux rates from treatment plots with wood chips were significantly larger than "no wood" control plots (1.71 \pm 0.05 versus $0.67 \pm 0.04 ; \mathrm{p}<0.001$; Fig. 5). There was no significant difference in the average total soil $\mathrm{CO}_{2}$ efflux between "no wood" control surface plots and "no wood" control buried plots ( $0.70 \pm 0.04$ versus $0.64 \pm 0.06$; Fig. 6). This demonstrates that the soil disturbance caused by burying the wood chips had no effect on average total soil $\mathrm{CO}_{2}$ efflux. No wood control values were left out of the final statistical analysis.

\section{Wood location}

Wood location had a significant effect on soil $\mathrm{CO}_{2}$ efflux rates (Table 6). The average total soil $\mathrm{CO}_{2}$ efflux rate for plots with wood chips located on the surface was twice that of plots with buried wood chips (2.28 $\pm 0.07 \mathrm{~g} \mathrm{CO}_{2} \mathrm{~m}^{-2} \mathrm{~h}^{-1}$ versus $1.14 \pm 0.05 \mathrm{~g} \mathrm{CO}_{2} \mathrm{~m}^{-2}$ $h^{-1}$, respectively; $\mathrm{p}<0.001$; Figs. 6 and 7). The wood-derived portion of soil $\mathrm{CO}_{2}$ efflux was also significantly higher from plots with wood chips located on the surface versus plots with buried wood chips ( $\mathrm{p}<0.001$; Fig. 7). The percentage of wood-derived soil $\mathrm{CO}_{2}$ efflux also differed significantly by wood location $(\mathrm{p}<0.001)$, with percent wood-derived 
soil $\mathrm{CO}_{2}$ efflux of $53 \pm 2 \%$ for plots with wood chips located on the surface and $43 \pm 2 \%$ for plots with buried wood chips.

\section{Temperature}

The temperature treatment had a significant effect on soil $\mathrm{CO}_{2}$ efflux rates (Table 6). Plots at ambient temperatures had lower average total soil $\mathrm{CO}_{2}$ efflux rates than those of passively warmed plots $\left(1.62 \pm 0.06 \mathrm{~g} \mathrm{CO}_{2} \mathrm{~m}^{-2} \mathrm{~h}^{-1}\right.$ versus $1.90 \pm 0.09 \mathrm{~g} \mathrm{CO}_{2} \mathrm{~m}^{-2} \mathrm{~h}^{-1}$, respectively; p=0.007; Fig. 7). There was a significant difference in the wood-derived portion of soil $\mathrm{CO}_{2}$ efflux between ambient and warmed treatments $(\mathrm{p}<0.001$; Fig. 7). This difference was only significant when wood chips were located on the surface and not when wood chips were buried ( $\mathrm{p}=0.0113$; Fig. 7). The average percentage of woodderived soil $\mathrm{CO}_{2}$ efflux also differed significantly by temperature treatment $(\mathrm{p}<0.001)$ with the percent wood-derived soil $\mathrm{CO}_{2}$ efflux of $46 \pm 2 \%$ for ambient temperature plots and $54 \pm 3 \%$ for warmed temperature plots.

The interaction of wood location and temperature was significant for the percentage of wood-derived soil $\mathrm{CO}_{2}$ efflux, with the average percentage of wood-derived soil $\mathrm{CO}_{2}$ efflux being significantly greater from plots exposed to the warming treatment only in plots where wood chips were buried ( $<<0.001$; Fig. 7). There was no significant difference between the overall percentages of wood-derived soil $\mathrm{CO}_{2}$ efflux from the elevated temperature treatment compared to the ambient temperature treatment in plots where wood chips were located on the surface.

\section{Fungal inoculation}

The fungal inoculation treatment had a minimally significant effect on soil $\mathrm{CO}_{2}$ efflux rates (Table 6). The average total soil $\mathrm{CO}_{2}$ efflux rates and the wood-derived portion of soil $\mathrm{CO}_{2}$ efflux did not significantly differ between fungal inoculation treatments, with an

average total soil $\mathrm{CO}_{2}$ efflux rate of $1.70 \pm 0.09 \mathrm{~g} \mathrm{CO}_{2} \mathrm{~m}^{-2} \mathrm{~h}^{-1}$ for brown rot, $1.63 \pm 0.08 \mathrm{~g}$ $\mathrm{CO}_{2} \mathrm{~m}^{-2} \mathrm{~h}^{-1}$ for white rot, and $1.77 \pm 0.08 \mathrm{~g} \mathrm{CO}_{2} \mathrm{~m}^{-2} \mathrm{~h}^{-1}$ for natural rot. The percentage of wood-derived soil $\mathrm{CO}_{2}$ efflux was significantly higher from plots with wood chips inoculated with natural rot compared to plots with wood chips inoculated with white rot 
( $52 \pm 3 \%$ versus $45 \pm 3 \%$; $\mathrm{p}=0.001$ ) The average percentage of wood-derived soil $\mathrm{CO}_{2}$ efflux from brown rot was $47 \pm 3 \%$ and did not significantly differ from white rot or natural rot.

The interaction between fungal inoculation and temperature was significant (Table 6). The average percentage of wood-derived soil $\mathrm{CO}_{2}$ efflux was significantly greater from passively warmed plots compared with that of ambient temperature only when wood chips were inoculated with brown rot ( $\mathrm{p}=0.0514$; Fig. 8). There was no significant difference between the warmed temperature treatment and the ambient temperature treatment when wood chips were inoculated with white or natural rot.

\section{Wood quality}

The wood quality treatments had a significant effect on soil $\mathrm{CO}_{2}$ efflux rates (Table 6). The average total soil $\mathrm{CO}_{2}$ efflux rate from elevated $\mathrm{CO}_{2}+\mathrm{O}_{3}$ wood quality treatment plots was significantly lower than the average total soil $\mathrm{CO}_{2}$ efflux rates from both the ambient and elevated $\mathrm{CO}_{2}$ wood quality treatment plots $\left(1.37 \pm 0.12 \mathrm{~g} \mathrm{CO}_{2} \mathrm{~m}^{-2} \mathrm{~h}^{-1}\right.$ versus $1.97 \pm 0.14 \mathrm{~g} \mathrm{CO}_{2} \mathrm{~m}^{-2} \mathrm{~h}^{-1}$ and $1.71 \pm 0.06 \mathrm{~g} \mathrm{CO}_{2} \mathrm{~m}^{-2} \mathrm{~h}^{-1}, \mathrm{p}=0.008$ and $\mathrm{p}=0.007$, respectively; Fig. 9). The wood-derived portion of soil $\mathrm{CO}_{2}$ efflux was significantly higher from plots with the elevated $\mathrm{CO}_{2}$ wood quality treatment compared to plots with the elevated $\mathrm{CO}_{2}+\mathrm{O}_{3}$ wood quality treatment ( $\mathrm{p}=0.002$; Fig. 9). The average percentage of wood-derived soil $\mathrm{CO}_{2}$ efflux was also significantly higher from plots with the elevated $\mathrm{CO}_{2}$ wood quality treatment compared to plots with the elevated $\mathrm{CO}_{2}+\mathrm{O}_{3}$ wood quality treatment ( $45 \pm 3 \%$ versus $42 \pm 5 \%$; $\mathrm{p}=0.004$ ).

\section{Soil texture}

Although soil texture did not have a statistically significant effect on soil $\mathrm{CO}_{2}$ efflux rates (Table 6), the average total soil $\mathrm{CO}_{2}$ efflux rates tended to be higher from loamy textured soils ( $\left.1.56 \pm 0.05 \mathrm{~g} \mathrm{CO}_{2} \mathrm{~m}^{-2} \mathrm{~h}^{-1}\right)$ compared with those from sandy textured soils $\left(1.35 \pm 0.08 \mathrm{~g} \mathrm{CO}_{2} \mathrm{~m}^{-2} \mathrm{~h}^{-1}\right)$. The wood-derived portion of soil $\mathrm{CO}_{2}$ efflux also tended to be higher from plots located on loamy textured soil sites ( $0.90 \pm 0.04$ versus $0.75 \pm 0.06$; p not significant). However, the percentage of wood-derived soil $\mathrm{CO}_{2}$ efflux differed 
significantly by soil texture $(\mathrm{p}<0.001)$, with percent wood-derived soil $\mathrm{CO}_{2}$ efflux of $44 \pm$ $3 \%$ for sandy texture compared with $50 \pm 2 \%$ for the loamy texture.

The interaction of soil texture and wood location was significant for the average total soil $\mathrm{CO}_{2}$ efflux (Table 6), with soil $\mathrm{CO}_{2}$ efflux being greater for loamy textured soils compared with sandy soils only when wood chips were buried (1.21 \pm 0.07 versus $0.92 \pm$ $0.05 ; \mathrm{p}=0.042$ ). There was no significant difference between average total soil $\mathrm{CO}_{2}$ efflux from plots located on loamy textured soils and plots on sandy textured soils when wood chips were located on the surface ( $2.27 \pm 0.08$ versus $2.33 \pm .15$ ).

\subsection{Soil Water DOC}

The average total DOC values are an average of all DOC measurements across 2 growing seasons. The percentage of wood-derived DOC (Equ. 2) is an indication of how much wood is being decomposed independent of total DOC values. The wood-derived portion of DOC was created by multiplying total DOC by the percentage of woodderived DOC for a given measurement period. All averages are expressed \pm 1 standard error. The total DOC contents ranged from 3.84 to $71.40 \mathrm{mgL}^{-1}$ in the 2013 and 2014 growing seasons. The wood-derived portion of the total DOC content was about half the total DOC, ranging from 0.01 to $38.80 \mathrm{mgL}^{-1}$.

\section{Fungal inoculation}

The fungal inoculation treatment had a significant effect on total DOC (Table 7). The average total DOC content for plots inoculated with brown rot was significantly lower than both plots inoculated with white rot and plots inoculated with natural rot (7.80 \pm $0.92 \mathrm{mgL}^{-1}$ versus $19.37 \pm 3.19 \mathrm{mgL}^{-1}$ and $20.69 \pm 2.97 \mathrm{mgL}^{-1}$, respectively; $\mathrm{p}=0.005$;

Fig. 10). The average percentage of wood-derived DOC was lower from plots where wood chips were inoculated with brown rot compared to either natural rot or white rot (7 $\pm 4 \%$ versus $21 \pm 2 \%$ and $25 \pm 6 . \%$, respectively; $\mathrm{p}=0.011$; Fig. 10 ).

The fungal inoculation treatment also had a significant effect on the composition of DOC. Plots inoculated with brown rot showed significantly less humification than white rot inoculation plots ( $1.67 \pm 0.88$ versus $6.31 \pm 1.01$; $\mathrm{p}=0.024$; Fig. 11$)$ and significantly 
less tannin content than both white and natural rot inoculation plots $(1.37 \pm 0.29$ versus $2.47 \pm 0.47$ and $3.04 \pm 0.62$, respectively; $p=0.057$ and $p=0.023$; Fig 11). Although not statistically significant, plots inoculated with brown rot tended to have soil water DOC that was more aromatic and had larger molecular size than white rot inoculation plots (5.09 \pm 1.46 versus $4.52 \pm 0.61$ and $2.72 \pm 0.38$ versus $1.87 \pm 0.30$, respectively.

The interaction between fungal inoculation and wood location was significant. There was a significant difference between the wood-derived portion of DOC in plots inoculated with natural rot and plots inoculated with brown rot only when wood chips were located on the surface $(11.20 \pm 3.16$ versus $0.85 \pm 0.50 ; \mathrm{p}=0.0374)$. There was no significant difference between natural and brown rot inoculation treatments when the wood chips were buried (3.02 \pm 0.81 versus $0.21 \pm 0.07)$.

\section{Temperature}

The interaction between fungal inoculation and temperature was significant (Table 7). The average total DOC was lower from plots where wood chips were inoculated with brown rot compared to plots were wood chips were inoculated with white rot in the ambient temperature treatment plots, not in the passively warmed temperature treatment $7.75 \pm 1.17$ versus $26.71 \pm 4.05 ; \mathrm{p}=0.002$; Fig. 12). Plots in which wood chips were inoculated with natural rot had higher average total DOC than plots where wood chips were inoculated with white rot and brown rot, only in plots that were exposed to the passively warmed temperature treatment, not the ambient temperature treatment $(24.14 \pm$ 4.64 versus $8.37 \pm 1.17$ and $7.85 \pm 1.50$, respectively; $p=0.027$ and $p=0.008$; Fig. 12).

The temperature treatment had a significant effect on the average specific ultraviolet absorbance (SUVA254), indicating aromaticity. SUVA254 was larger in plots exposed to the ambient temperature treatment compared to the passively warmed temperature treatment (5.30 \pm 0.77 versus $3.56 \pm 0.43$; $\mathrm{p}=0.054)$.

\section{Wood Quality}

The wood quality treatment had a significant effect on soil water characteristics. The average SUVA 254 from elevated $\mathrm{CO}_{2}$ wood quality plots was significantly higher than the average SUVA 254 from ambient wood quality treatment plots (4.95 \pm 0.51 versus $2.16 \pm$ 
0.42; $\mathrm{p}=0.013$ ). Plots with elevated $\mathrm{CO}_{2}$ wood quality also showed significant more humification than plots with ambient wood quality (4.90 \pm 0.70 versus $1.71 \pm 1.09$; $\mathrm{p}=0.050$ ). There was no significant difference between wood qualities in total DOC, molecular size, or total phenolics.

\section{Analysis of Covariance}

The relationship between total soil $\mathrm{CO}_{2}$ efflux rates and total DOC contents were significantly affected by fungal inoculations of brown rot, white rot, and natural rot (p=0.009; Fig. 13).

\subsection{FTIR Analysis}

At the onset of decomposition there was no significant difference between in the proportion of lignin:carbohydrates across fungal inoculation treatments. After 12 months of decomposition the average proportion of lignin:carbohydrates increased from $0.50 \pm$ 0.01 to $0.53 \pm 0.02$ in wood inoculated with brown rot and from $0.51 \pm 0.01$ to $0.52 \pm$ 0.01 in wood inoculated with natural rot. The average proportion of lignin:carbohydrates decreased from $0.49 \pm 0.01$ to $0.48 \pm 0.01$ in wood inoculated with white rot. After 12 months of decomposition the proportion of lignin:carbohydrates was significantly lower in wood inoculated with white rot compared with wood inoculated with brown rot for all wood qualities ( $\mathrm{p}=0.001$; Fig. 14).

After 12 months of decomposition, we found differences in the proportion of lignin:carbohydrates between fungal inoculation treatments depending on the wood quality treatment. The proportion of lignin:carbohydrates was highest in wood inoculated with brown rot for ambient and elevated $\mathrm{CO}_{2}+\mathrm{O}_{3}$ wood qualities, and highest in natural rot for the elevated $\mathrm{CO}_{2}$ wood quality. The data suggests that brown rot and natural rot selectively removed carbohydrates in ambient and elevated $\mathrm{CO}_{2}+\mathrm{O}_{3}$ wood qualities. There was no apparent preference for carbohydrates in neither brown nor natural rot in the elevated $\mathrm{CO}_{2}$ wood quality. The data also suggests that white rot selectively removed lignin in ambient and elevated $\mathrm{CO}_{2}+\mathrm{O}_{3}$ wood qualities. There was no apparent preference for lignin in the elevated $\mathrm{CO}_{2}$ wood quality because the proportion of 
lignin:carbohydrates after 12 months of decomposition relative to the onset of decomposition had increased.

There was no clear evidence for the demethylation of lignin. Though there were some decreases in the proportion of lignin demethylation peaks:reference lignin peak over 12 months of decomposition ( $\mathrm{I}_{1462} / \mathrm{I}_{1505}$ and $\left.\mathrm{I}_{1425} / \mathrm{I}_{1505}\right)$, all ratio decreases were small and could be contributed to other decay rather than the demethylation of lignin. 


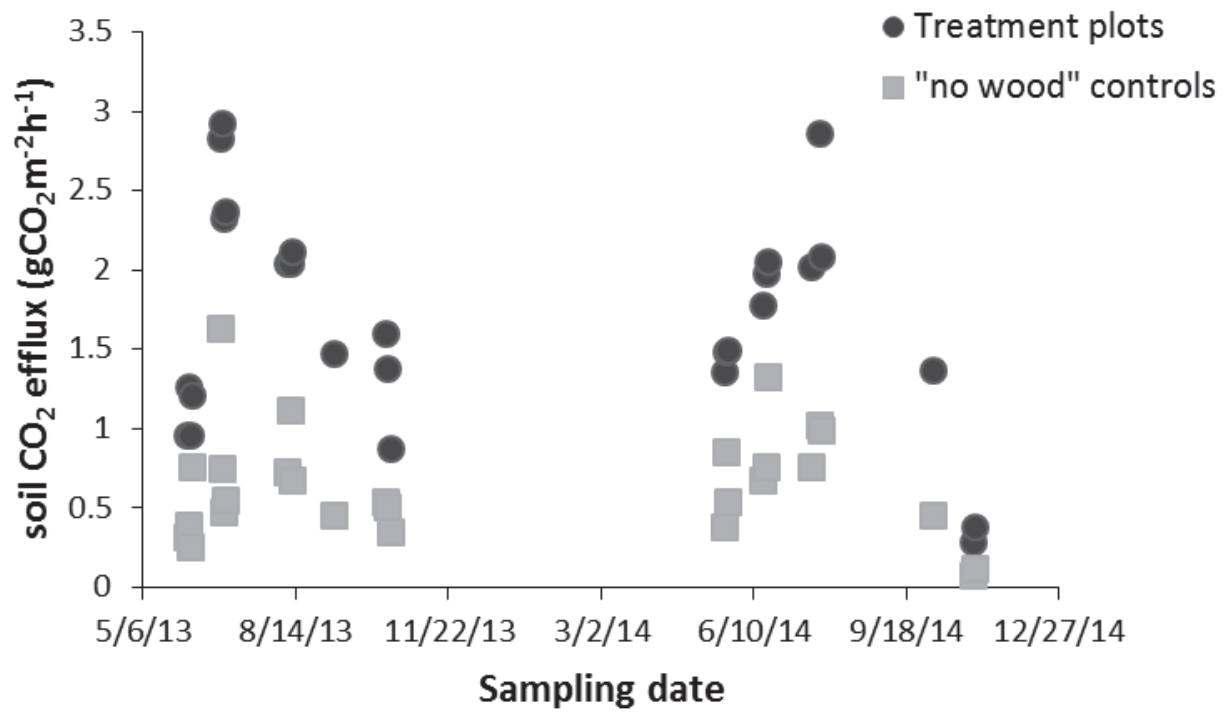

Fig. 5. Difference in average total soil $\mathrm{CO}_{2}$ efflux rates for experimental plots and control plots across two growing seasons $(p<0.001)$. 


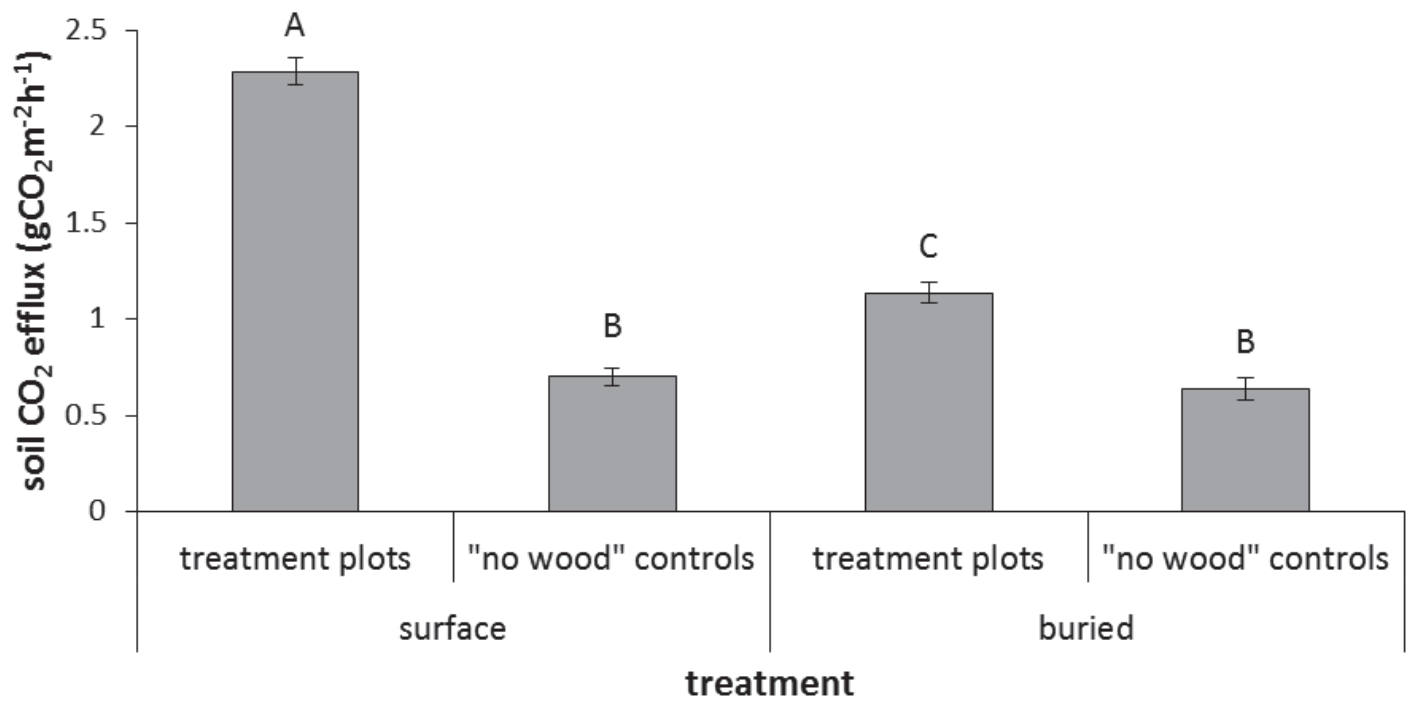

Fig. 6. Average total soil $\mathrm{CO}_{2}$ efflux rates from experimental and no wood control surface plots compared with experimental and no wood control buried plots. Different letters represent significant differences between average total soil $\mathrm{CO}_{2}$ efflux rates. 


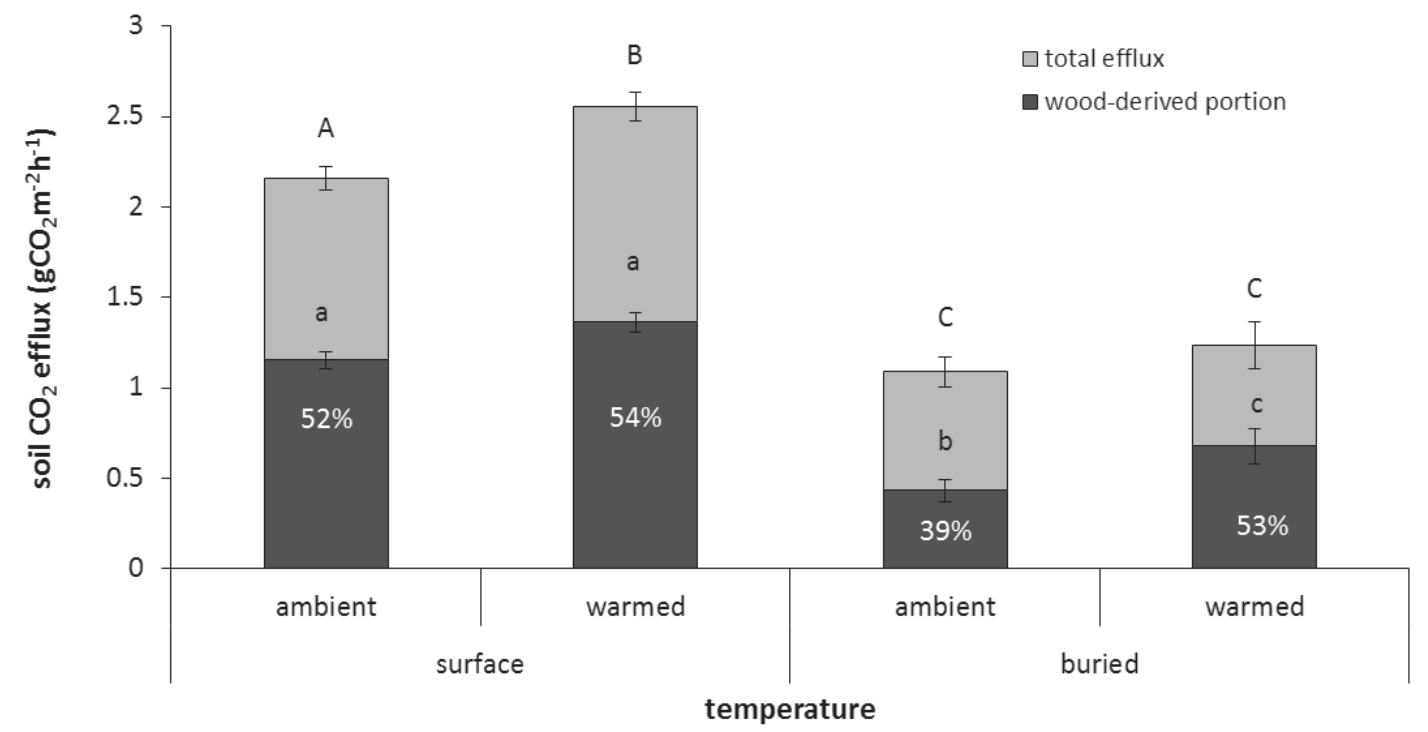

Fig. 7. Average total soil $\mathrm{CO}_{2}$ efflux rates and the portion of soil $\mathrm{CO}_{2}$ efflux derived from wood differed significantly by temperature treatment $(p=0.007, p<0.001$, respectively). This difference was only significant when wood chips were located on the surface and not when wood chips were buried $(p=0.011)$. Percentages are the average percentage of wood-derived soil $\mathrm{CO}_{2}$ efflux. These percentages differed significantly between ambient and warmed temperature treatments $(p<0.001)$. Uppercase letters represent significant differences between average overall soil $\mathrm{CO}_{2}$ efflux and lowercase letters represent significant differences between the portion of soil $\mathrm{CO}_{2}$ efflux derived from wood. 

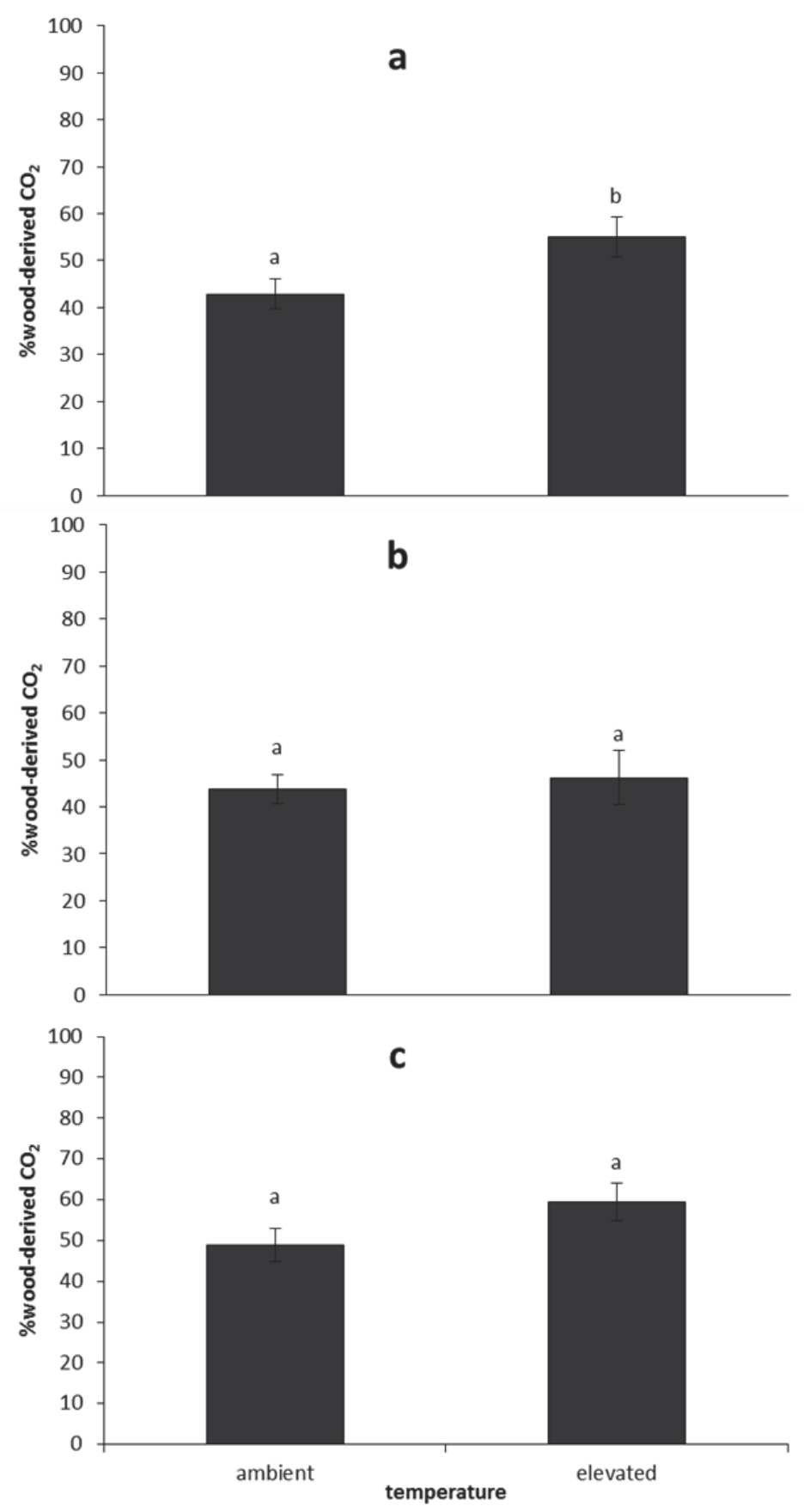

Fig. 8. The average percentage of wood-derived soil $\mathrm{CO}_{2}$ efflux differed significantly between elevated and ambient temperature treatment only when wood chips were inoculated with (a) brown rot $(p=0.051)$, but not for (b) white rot or (c) natural rot. Different letters represent significant differences between the average percentage of wood-derived soil $\mathrm{CO}_{2}$ efflux for each panel. 


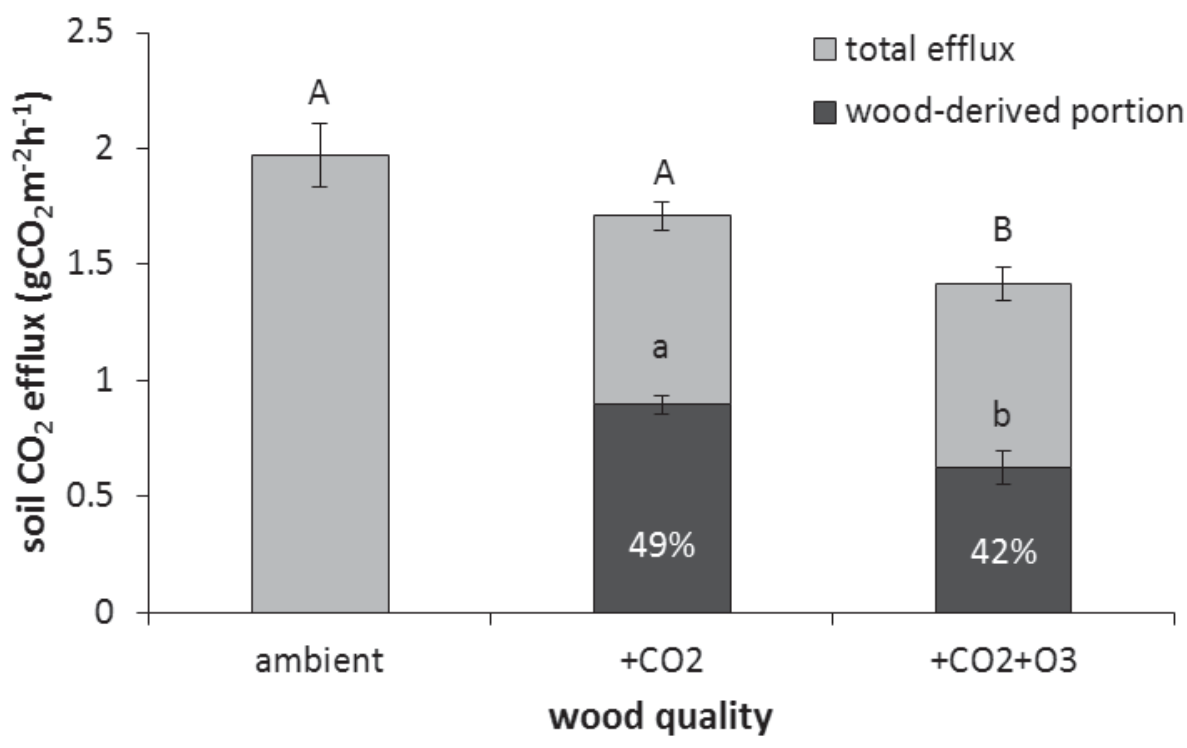

Fig. 9. Average total soil $\mathrm{CO}_{2}$ efflux rates from the ambient and the elevated $\mathrm{CO}_{2}$ wood quality treatment plots differed significantly from the elevated $\mathrm{CO}_{2}+\mathrm{O}_{3}$ wood quality treatment plots $(p<0.001$ and $p=0.007$, respectively). Percentages are the average percentage of wood-derived soil $\mathrm{CO}_{2}$ efflux. The portion of soil $\mathrm{CO}_{2}$ efflux derived from wood and the average percentage of wood-derived soil $\mathrm{CO}_{2}$ efflux was significantly greater from the elevated $\mathrm{CO}_{2}$ wood quality treatment plots compared with the elevated $\mathrm{CO}_{2}+\mathrm{O}_{3}$ wood quality treatment plots ( $\mathrm{p}=0.002$ and $\mathrm{p}=0.004$, respectively). Uppercase letters represent significant differences between average total soil $\mathrm{CO}_{2}$ efflux rates and lowercase letters represent significant differences between the portion of soil $\mathrm{CO}_{2}$ efflux derived from wood. 


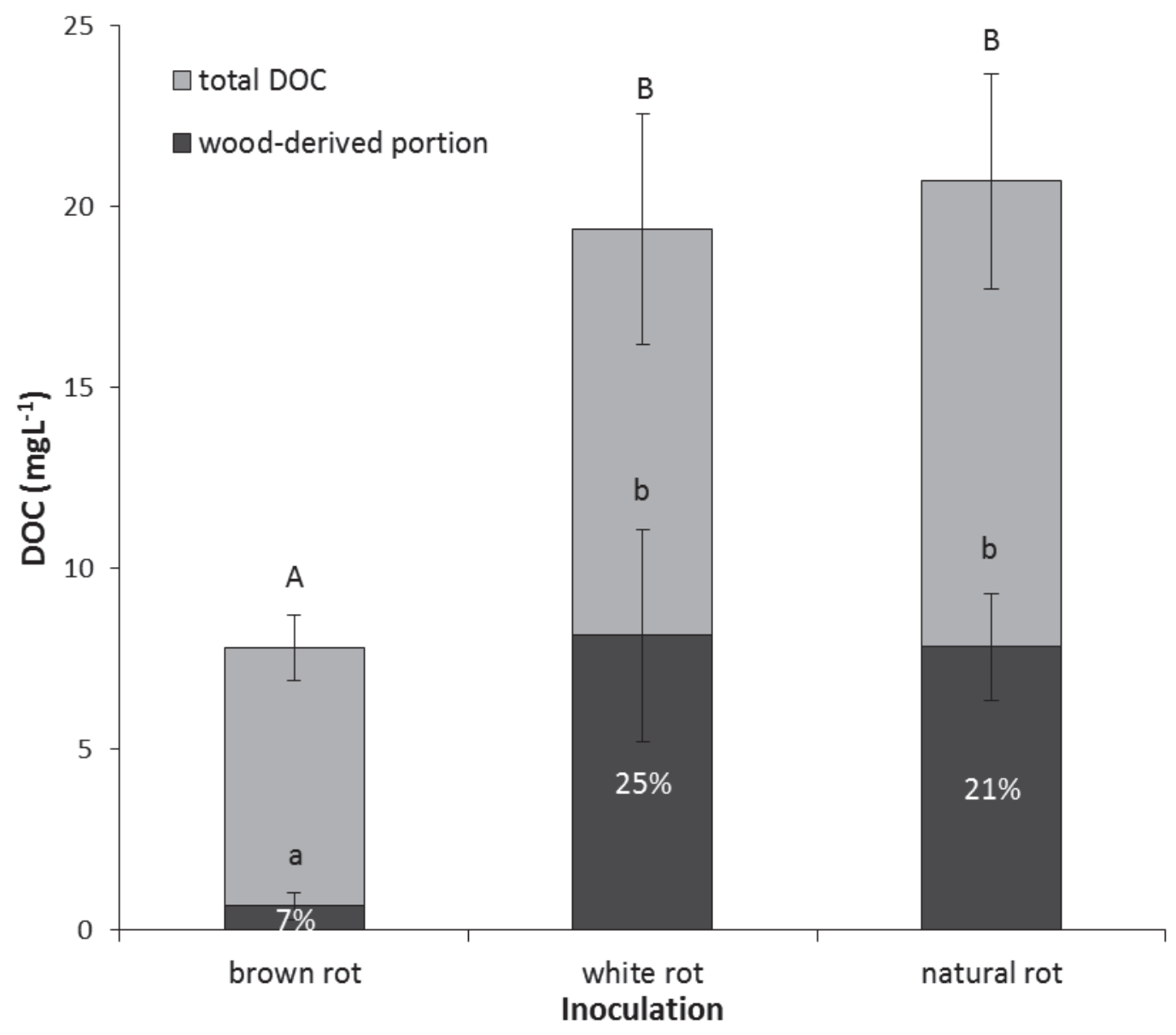

Fig. 10. Average total DOC differed significantly between inoculation treatments. Average total DOC from plots containing wood chips inoculated with natural rot and white rot were significantly greater than plots containing wood chips inoculated with brown rot $(p=0.005$ and $p=0.011$, respectively). Percentages are the average percentage of wood-derived DOC. These percentages were significantly higher from both natural rot and white rot inoculation plots compared to brown rot inoculation plots $(p=0.011)$. Uppercase letters represent significant differences between average total DOC and lowercase letters represent significant differences between the portion of DOC derived from wood. 

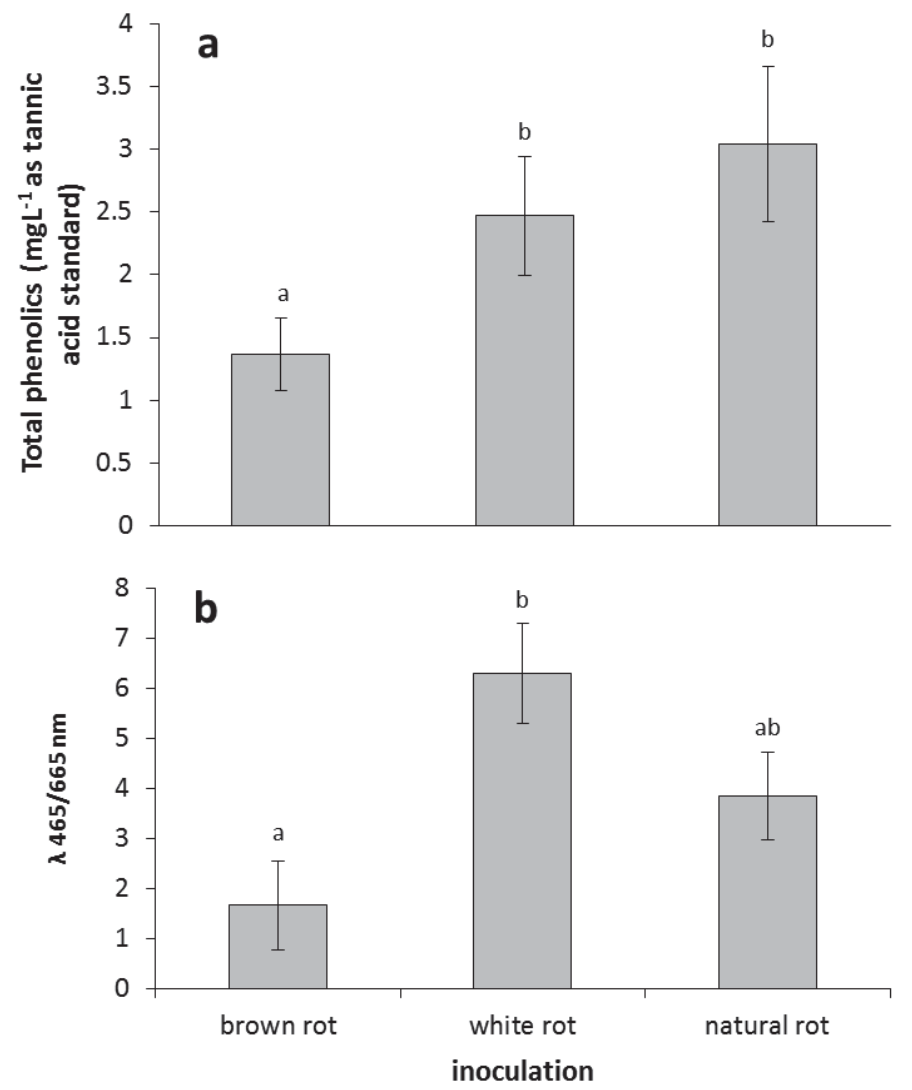

Fig. 11. Total phenolics (a) and average degree of humification (b) was significantly different between inoculation treatments. Plots inoculated with brown rot had less total phenolics than both white rot and natural rot inoculation plots ( $p=0.057$ and $p=0.023$, respectively). Plots with brown rot showed less humification than plots inoculated with white rot $(p=0.024)$. Different letters represent significant differences between inoculation treatments. 


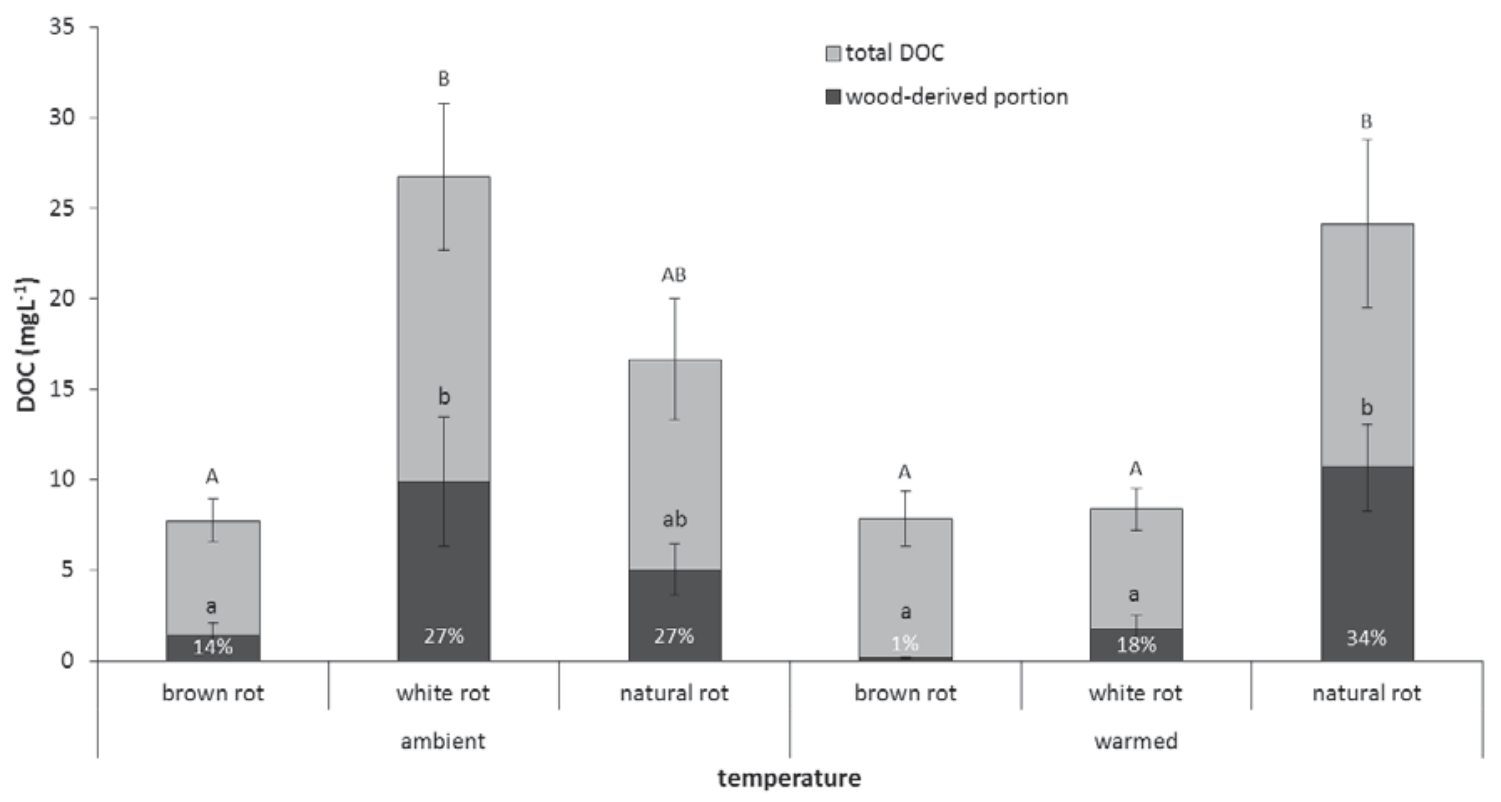

Fig. 12. The average total DOC differed significantly between plots with white rot inoculum and brown rot inoculum only when the plots were exposed to ambient temperatures $(p=0.002)$. The average total DOC from plots containing wood chips inoculated with natural rot were significantly greater than plots containing either wood chips inoculated with white or brown rot only when plots were exposed to the warmed temperature treatment $(p=0.027$ and $p=0.008$, respectively). Percentages are the average percentage of wood-derived DOC. Uppercase letters represent significant differences between total DOC averages and lowercase letters represent significant differences between the portion of total DOC derived from wood. 


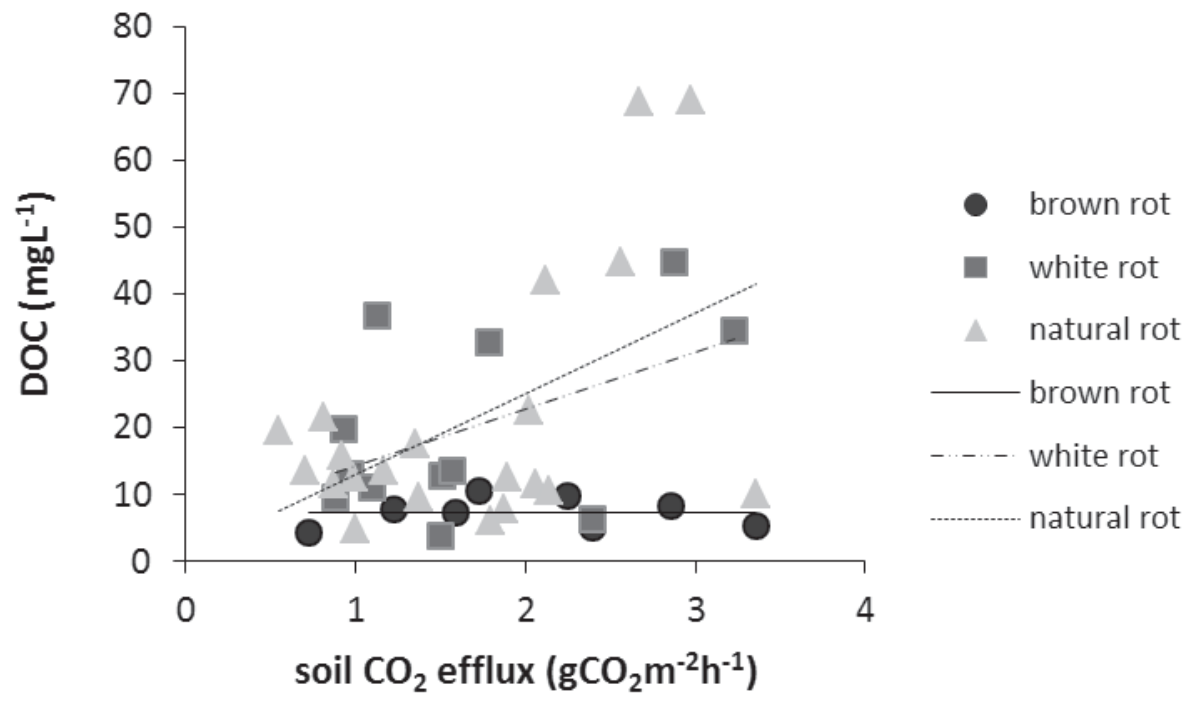

Fig. 13. The relationship between total soil $\mathrm{CO}_{2}$ efflux rates $\left(\mathrm{g} \mathrm{CO}_{2} \mathrm{~m}^{-2} \mathrm{~h}^{-1}\right)$ and total DOC contents (mgL-1) were significantly affected by fungal inoculation of brown rot, white rot, and natural rot ( $F$-value $=4.14$, $\mathrm{p}=0.009$ ) 


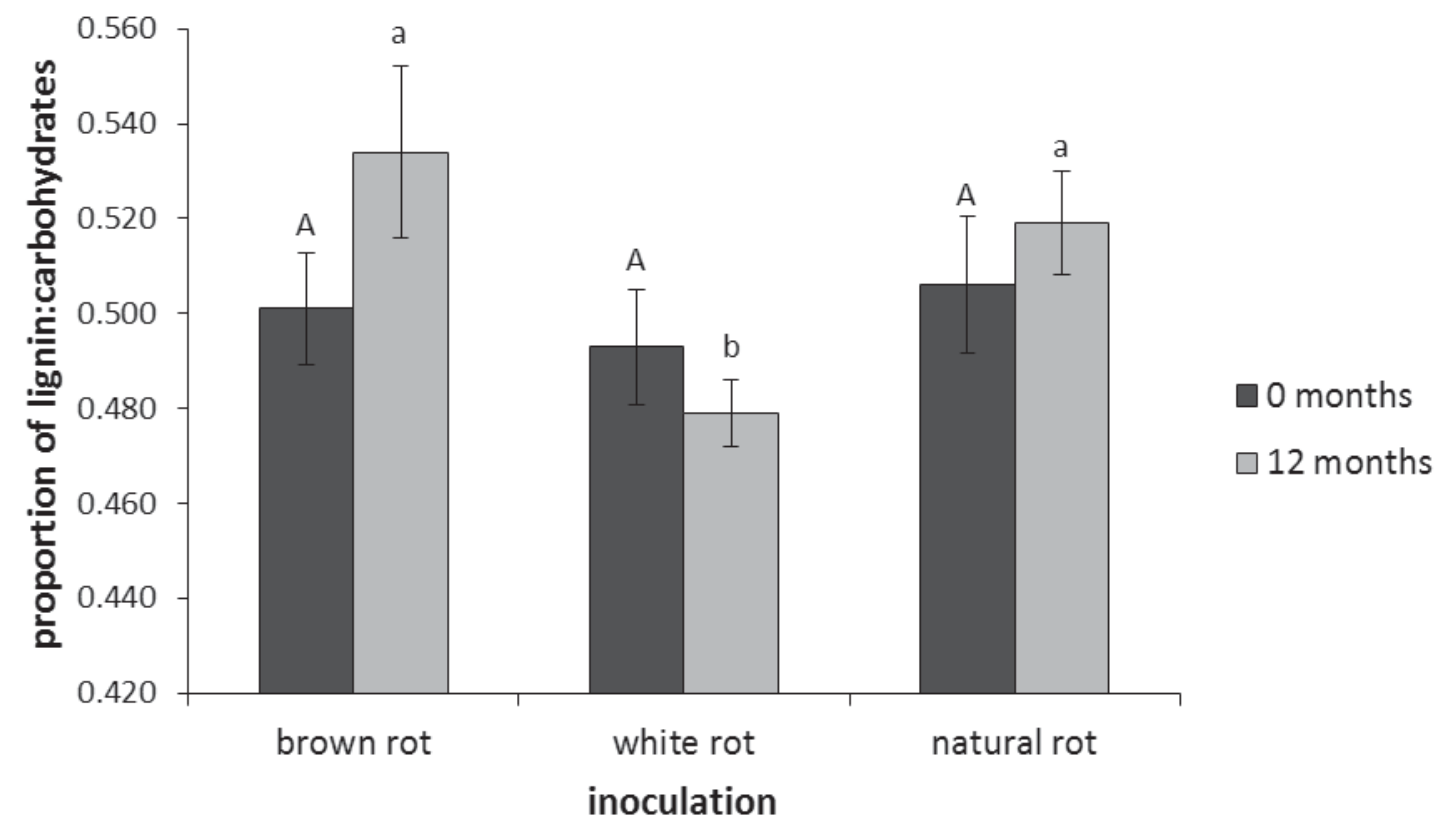

Fig. 14. Proportions of the lignin reference peak intensity $\left(1505 \mathrm{~cm}^{-1}\right)$ to carbohydrate reference peak intensities (1738 $\mathrm{cm}^{-1}$, hemicellulose; $1375 \mathrm{~cm}^{-1}$, cellulose and hemicellulose; $1158 \mathrm{~cm}^{-1}$, cellulose and hemicellulose; and $898 \mathrm{~cm}^{-1}$, cellulose) at 0 months and after 12 months of decomposition by brown rot, white rot, and natural rots. White rot had a significantly lower proportion of lignin:carbohydrates compared to brown and natural rots $(p=0.001)$. Uppercase letters represent significant differences between proportions of lignin:carbohydrates at 0 months and lowercase letters represent significant differences between proportion of lignin:carbohydrates after 12 months of decomposition. 


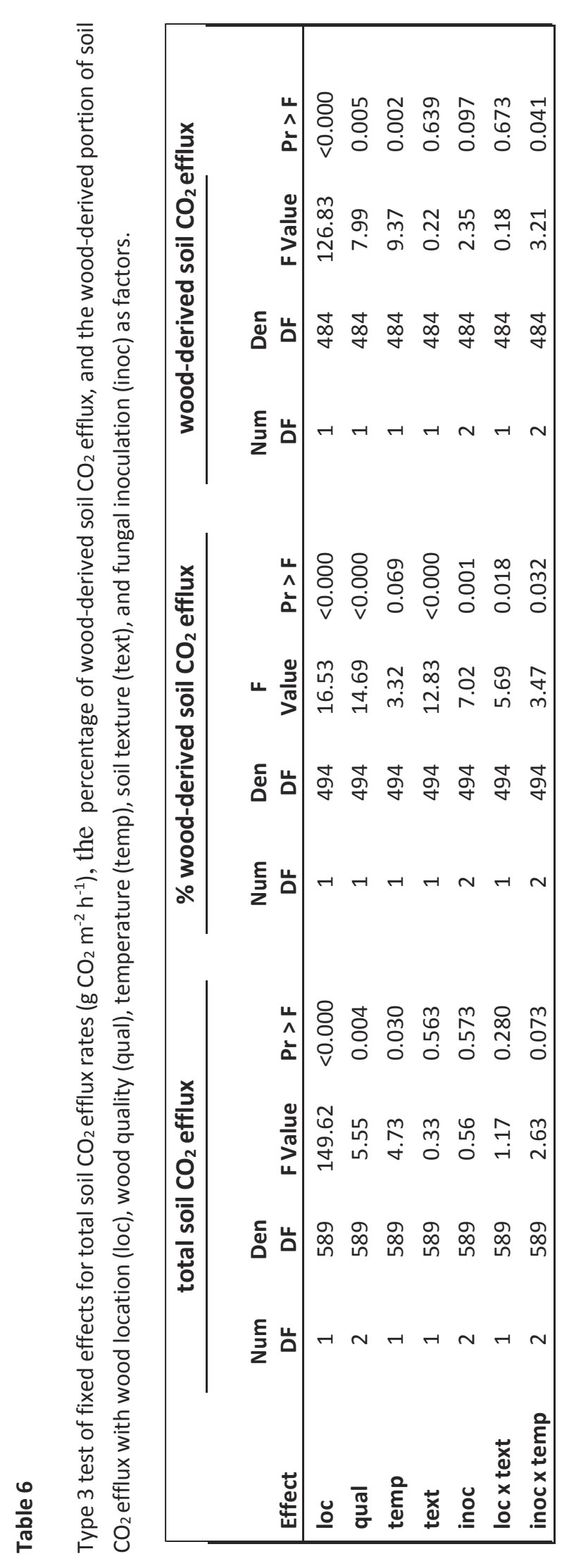




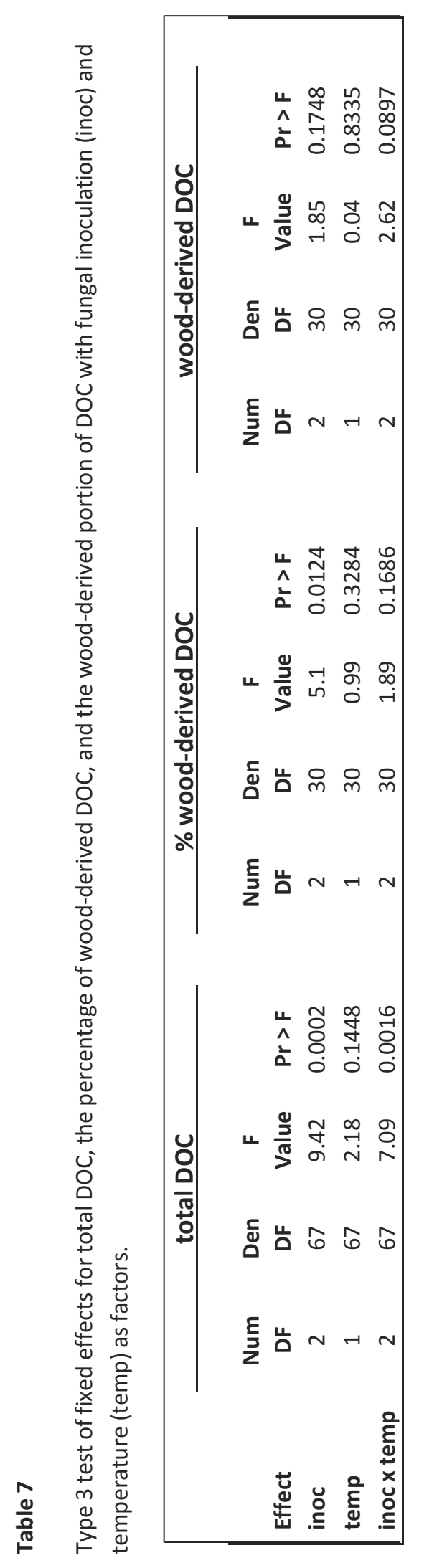




\section{Discussion}

Our measurements of average soil $\mathrm{CO}_{2}$ efflux rates, ranging from 0.28 to $2.92 \mathrm{~g} \mathrm{CO}_{2}$ $\mathrm{m}^{-2} \mathrm{~h}^{-1}$, are similar to other soil $\mathrm{CO}_{2}$ efflux rates reported for northern forest soils in

general, ranging from 0.02 to $7.26 \mathrm{~g} \mathrm{CO}_{2} \mathrm{~m}^{-2} \mathrm{~h}^{-1}$ (Bowden et al., 1993; Raich and Schlesinger, 1992; Singh and Gupta, 1977). However, our average soil $\mathrm{CO}_{2}$ efflux rates are higher than those reported for other aspen forests during the growing season (i.e. 0.09 to $0.90 \mathrm{~g} \mathrm{CO}_{2} \mathrm{~m}^{-2} \mathrm{~h}^{-1}$; King et al., 2001; Wang et al., 2006; Pregitzer et al., 2008). Our "no wood" control plots had a lower range of soil $\mathrm{CO}_{2}$ efflux rates (0.07 to $1.63 \mathrm{~g} \mathrm{CO}_{2}$ $\mathrm{m}^{-2} \mathrm{~h}^{-1}$ ) compared to our treatment plots, providing soil $\mathrm{CO}_{2}$ efflux rates more comparable to those from the other aspen forest soils. The higher soil $\mathrm{CO}_{2}$ efflux from treatment plots resulted from the decomposition of additional wood chip carbon. Others have seen similar trends of increased soil $\mathrm{CO}_{2}$ efflux after the addition of litter (Crow et al., 2009; Sulzman et al., 2005).

\section{Wood Location}

Plots with surface wood chips had significantly larger wood-derived soil $\mathrm{CO}_{2}$ efflux rates than plots with buried wood chips, supporting my original hypothesis (Hypothesis 4). I expected to find greater wood-derived carbon losses in surface wood chip plots, because belowground residues have been found to increase chemical associations formed between organic matter and mineral surfaces at greater depths, reducing decompositional losses of $\mathrm{CO}_{2}$ (Rasse et al., 2001). Similar to our findings, others have shown $\mathrm{CO}_{2}$ production to be greatest on the soil surface, with $\mathrm{CO}_{2}$ production decreasing with depth, likely resulting from the amount of oxygen decreasing with depth (Singh and Gupta, 1977; Jorgensen and Wells, 1973).

DOC from surface plots was larger than DOC from buried plots, but unfortunately lysimeters were not long enough to reach below buried wood chips, which likely missed wood-derived DOC leaching from buried wood chips (Hypothesis 5). This significant finding was determined to be inconclusive. Therefore, no significant difference was shown between wood-derived DOC content in surface and buried wood chips, contrary to my original hypothesis. 
Based on our data, wood location had the largest treatment effect on wood-derived carbon losses, with buried wood treatments showing the smallest losses. This is similar to what Huang and Spohn, 2015 demonstrated: roots are more important than aboveground litter in influencing belowground processes, such as SOC losses and overall stabilization (Huang and Spohn, 2015). Others have also demonstrated that roots significantly add to the carbon pool in mineral soils (Hansson et al., 2010). Root carbon is decomposed and mineralized at a slower rate compared to other litter carbon. The slower decomposition rates can be attributed to lower litter quality and less labile components in roots (Palviainen et al., 2004). Our buried wood chips acted similarly to roots in that they produced fewer carbon losses and likely decomposed more slowly. However if actual root material had been used, the results may have been different. These findings indicate that not only does the source of carbon influence decomposition rates; the physical location of carbon can also influence decomposition.

Shoots may not be the most appropriate surrogate for roots, especially fine roots. Roots behave differently from shoots because roots release compounds that are very reactive, forming strong complexes with hydroxyl groups found in the soil (Rasse et al., 2005). Root hairs can also physically input organic matter into aggregates, physically protecting SOC from microbial decay (Rasse et al., 2005). Not only is there greater accessibility for microbes in belowground residues, root carbon is more likely to be stabilized through mineral bonding in belowground residues. In fact, in temperate forests, roots tend to add 2.5 times more organic matter than shoots to the soil (Leff et al., 2012). If root carbon had been used, it is likely that we would have seen even slower decomposition rates.

\section{Temperature}

The OTCs significantly warmed the soil surface by about $0.7^{\circ} \mathrm{C}(18.0 \pm 0.4$ compared to $17.3 \pm 0.4{ }^{\circ} \mathrm{C}$ ) for warmed and ambient temperature plots, respectively; $\mathrm{p}=0.09$ ) The OTCs were less effective at depth, only warming the soil by an average of $0.4{ }^{\circ} \mathrm{C}$, with no statistical significance between the warmed and ambient temperature plots (15.3 \pm 0.3 compared to $14.9 \pm 0.3^{\circ} \mathrm{C}$, respectively). The effectiveness of the 
OTCs was lowered because of shading from regenerating vegetation growing in our research sites. Although, shading occurred, the OTCs could have had other environmental effects, like reducing wind and/or increasing humidity with ramifications for the soil and near surface environment and ecology.

Although the warming effect was small, the wood-derived soil $\mathrm{CO}_{2}$ efflux rates were higher in the warmed plots compared to ambient temperature plots, supporting my original hypothesis (Hypothesis 6). The percentage of wood-derived soil $\mathrm{CO}_{2}$ efflux was also significantly higher in warmed temperature treatment plots but only when wood chips were buried. It is well documented that temperature has a large effect on decomposition rates. Typically, higher temperatures result in greater decomposition (Chen et al., 2013; Kirschbaum, 1995).

Wood-derived DOC content was not significantly different between temperature treatments. However, there was an interaction effect between the temperature and fungal inoculation treatments. Plots with white rot had more wood-derived DOC than plots with brown rot only in the ambient temperature treatment plots, not in warmed temperature treatment plots. DOC was less aromatic in warmed plots, possibly indicating greater decomposition. Aromaticity is an indication of decomposition, with more aromatic compounds indicating less decomposition and fewer aromatic compounds indicating more decomposition (Kalbitz et al., 2006).

Other metrics indicate that less decomposition occurred in the warmed temperature treatment plots, like less humification and larger molecular size. Typically, smaller molecular size indicates a greater level of decomposition (Kalbitz et al., 2006). More data, such as more frequent soil water sampling, might show a stronger interaction between temperature and fungal inoculation. For example, decomposition may increase under warmer temperatures, but the type of wood components being decomposed by different wood rotting fungi significantly affects the molecular size remaining in the soil water. Therefore the molecular size throughout the soil water may not be the most accurate predictor of decomposition.

At ambient temperatures, soil $\mathrm{CO}_{2}$ efflux rates tended to be higher in plots inoculated with white rot compared to brown rot (data not shown), but there was no measurable difference between soil $\mathrm{CO}_{2}$ efflux rates between white and brown rot in warmed 
temperature treatments. There are a couple explanations as to why this was observed. As temperatures rise, low quality carbon components are more readily available to microbes (Conant et al., 2011), which would increase the efficiency of decomposition for both white rot and brown rot. Enzyme activities, including lignin-degrading enzymes, also tend to increase with increasing temperatures (Feng et al., 2008; Conant et al., 2011), again increasing decomposition efficiency for all decomposers, especially lignin decomposing white rot.

\section{Fungal Inoculation}

There was no significant difference in wood-derived soil $\mathrm{CO}_{2}$ efflux between fungal inoculation treatments. The average percentage of soil $\mathrm{CO}_{2}$ efflux derived wood tending to be larger in plots inoculated with white rot, but when applied to the average total soil $\mathrm{CO}_{2}$ efflux rates, the wood-derived soil $\mathrm{CO}_{2}$ efflux was larger in plots with brown rot compared to plots with white rot, not supporting my original hypothesis (Hypothesis 1). Plots with natural rot tended to have the largest wood-derived soil $\mathrm{CO}_{2}$ efflux of all three inoculation treatments.

Although carbon losses through soil $\mathrm{CO}_{2}$ efflux were not significantly affected by the fungal inoculation treatment, DOC carbon losses were. Wood-derived DOC content was larger from plots with white rot compared to plots with brown rot, also supporting original hypothesis (Hypothesis 1). DOC in the soil water from plots inoculated with brown rot appeared to be less decomposed than DOC from plots inoculated with white rot. There was less total DOC and the degree of humification was less in plots with brown rot. Also, plots inoculated with brown rot had less total phenolics present, likely because less phenolic material was released from decomposition. The molecular size of the soil water and the presence of aromatic compounds were slightly greater in plots with brown rot compared to plots with white rot, indicating less decomposition.

Plots with natural rot had larger wood-derived soil $\mathrm{CO}_{2}$ efflux and wood-derived DOC. This is likely because natural rot has a combination of brown rot and white rot communities increasing overall decomposition. While wood-derived DOC content was larger in plots with white rot compared to plots with brown rot, less data was collected from plots with brown rot, because either plots had no soil water to collect during 
sampling, or DOC contents were too small to analyze further for their wood-derived portions. Despite the smaller sample size for the brown rot, the results were consistent across the data and standard errors were small.

The average proportion of lignin:carbohydrates increased in wood decomposed by brown rot and decreased in wood decomposed by white rot during laboratory incubations, supporting original hypothesis (Hypothesis 2). Since white rot fungi are able to fully decompose lignin, unlike brown rot, it is to be expected that lignin would be removed from wood decomposed by white rot fungi and not in wood decomposed by brown rot fungi. Pandey and Nagveni, 2007 and Xu et al., 2013 found similar proportional lignin increases and decreases from both brown rot and white rot.

\section{Wood Quality}

Wood-derived soil $\mathrm{CO}_{2}$ efflux was lowest in elevated $\mathrm{CO}_{2}+\mathrm{O}_{3}$ wood quality treatments, contrary to my original hypothesis (H7). The original hypothesis was based on the mass loss data from one type of aspen clone, which was not representative of all the aspen FACE clones used in this study. Others have demonstrated that mass loss from carbon pools was greater under elevated $\mathrm{CO}_{2}$ compared to elevated $\mathrm{CO}_{2}+\mathrm{O}_{3}$. The findings from Loya et al., 2003 showed that elevated $\mathrm{O}_{3}$ significantly reduced decomposition, which was not negated by additions of $\mathrm{CO}_{2}$. These findings align more closely to the elevated $\mathrm{CO}_{2}+\mathrm{O}_{3}$ wood quality results of this study. Soil $\mathrm{CO}_{2}$ efflux rates were lower in elevated $\mathrm{CO}_{2}$ wood quality treatment plots compared to ambient wood quality. This is unlike other studies' findings, where elevated $\mathrm{CO}_{2}$ levels increased soil $\mathrm{CO}_{2}$ efflux substantially, ranging from a 2-49\% increase in soil efflux (King et al., 2004; Bernhardt et al., 2006; Pregitzer et al., 2008). Overall, elevated $\mathrm{CO}_{2}+\mathrm{O}_{3}$ wood quality had significantly fewer carbon losses as soil $\mathrm{CO}_{2}$ efflux than both elevated $\mathrm{CO}_{2}$ and ambient wood qualities.

There was no difference in soil $\mathrm{CO}_{2}$ efflux or DOC losses between ambient and elevated $\mathrm{CO}_{2}$ wood quality treatments, supporting original hypothesis. Elevated $\mathrm{CO}_{2}$ wood quality did not increase decomposition, like other studies suggest (Loya et al., 2003). However, others have demonstrated that elevated $\mathrm{CO}_{2}$ and elevated $\mathrm{O}_{3}$ had little effect on DOC concentrations, with a high level of variability across measurements (King 
et al., 2001). DOC losses were not assessed from the elevated $\mathrm{CO}_{2}+\mathrm{O}_{3}$ wood quality. Our wood was grown in elevated $\mathrm{CO}_{2}$ and $\mathrm{O}_{3}$ and then applied to the soil, looking at wood quality effects; other FACE studies were looking at atmospheric effects of elevated $\mathrm{CO}_{2}$ and $\mathrm{O}_{3}$, which is likely the reasoning behind the differing results in this study.

\section{Soil Texture}

Finer textured soils had similar wood-derived soil $\mathrm{CO}_{2}$ efflux rates compared to coarse textured soils, unlike original hypothesis, but not significantly so (Hypothesis 3). The percentage of wood-derived soil $\mathrm{CO}_{2}$ efflux was significantly larger in finer textured soils, but when applied to the average total soil $\mathrm{CO}_{2}$ efflux rates, it was not significant. Carbon losses tend to be greater in coarse textured soils, with less clay content and less physical protection of carbon (Kaiser and Guggenberger, 2003). Overall, soil texture had very little impact on decomposition in this study. This is likely because litter quality tends to be more important for controlling decomposition rates in the early stages of decomposition. Whereas organo-mineral interactions and physical carbon protection within soil aggregates become more important for controlling decomposition rates in the later stages of decomposition (Von Lützow et al., 2006). 


\section{Conclusions \& Future Directions}

\section{Conclusions}

In conclusion, the major effects demonstrated in this study show that wood-derived carbon matters in forest soils. The biggest finding in this study was attributed to wood location effects. The buried wood treatments had smaller amounts of wood-derived carbon losses than surface wood treatments. This may indicate the importance of buried wood, such as lignified coarse roots, for overall stabilization and storage of SOC. Coarse wood decomposition and the contribution to carbon losses and carbon stabilization needs to be studied more extensively and added to overall carbon models. Also, logging operations need to be cognizant of the importance of wood carbon, especially buried wood carbon, when making decisions about removing biomass from forest ecosystems.

The type of fungal community also had an effect on wood-derived carbon losses. Decomposers are an important factor in the early stages of decomposition and therefore need to be incorporated into both carbon loss models and carbon storage models. While it is unlikely that forests will ever be managed for fungal community, it is still important to understand how each wood-decomposing fungi effects carbon losses.

Factors associated with climate change also influenced carbon losses in this study. While elevated $\mathrm{CO}_{2}$ and elevated $\mathrm{CO}_{2}+\mathrm{O}_{3}$ wood qualities did not increased carbon losses, warmed temperatures did significantly increase carbon losses. Currently, more focus surrounds the effects of elevated $\mathrm{CO}_{2}$ and elevated $\mathrm{CO}_{2}+\mathrm{O}_{3}$ on aboveground processes and how those may effect belowground decomposition and carbon allocation. Because this study found wood-derived carbon loss differences between wood quality treatments, the influence of changes in atmospheric concentrations on wood quality associated with climate change need to be analyzed more thoroughly.

\section{Future Directions}

In the future, this study hopes to not only continue measuring wood-derived carbon losses, but to also measure where wood-derived carbon is found throughout different soil fractions. By looking at the heavy fraction of the soil, we can determine if the traceable 
wood carbon is being stabilized in the soil, which could inform about the overall stabilization of wood-derived carbon in forest soils. This study also hopes to perform a fungal DNA analysis on the wood chips after they have been decomposing in the field for two years. We hope to find that our fungal inoculation treatment is still relevant and working properly. This analysis could also inform about any fungal community shifts associated with the decomposition of wood-derived carbon. 


\section{Literature Cited}

Amthor, J.S. and members of the Ecosystems Working Group, 1998. Terrestrial Ecosystem Responses to Global Change: a research strategy. ORNL Technical Memorandum 1998/27, Oak Ridge National Laboratory, Oak Ridge, Tennessee pp. 37.

Atwell, B.J., Henery, M.L., Whitehead, D., 2003. Sapwood development in Pinus radiata trees grown for three years at ambient and elevated carbon dioxide partial pressures. Tree Physiol. 23, 13-21.

Baldrian, P., Valaskova, V., 2008. Degradation of cellulose by basidiomycetous fungi. FEMS Microbiol. Rev. 32, 501-521.

Bernhardt, E.S., Barber, J.J., Pippen, J.S., Taneva, L., Andrews, J.A., Schlesinger, W.H., 2006. Long-term effects of free air $\mathrm{CO}_{2}$ enrichment (FACE) on soil respiration. Biochem. 77, 91-116.

Blaschke, L., Forstreuter, M., Sheppard, L.J., Leith, I.K., Murray, M.B., Polle, A., 2002. Lignification in beech (Fagus sylvatica) grown at elevated $\mathrm{CO}_{2}$ concentrations: interaction with nutrient availability and leaf maturation. Tree Physiol. 22, 469477.

Boddy, L.,Watkinson, S.C., 1995.Wood decomposition, higher fungi, and their role in nutrient redistribution. Can. J. Bot. 73, 1377-1383.

Bowden, R.D., Nadelhoffer, K.J., Boone, R.D., Melillo, J.M., Garrison, J.B., 1993. Contributions of aboveground litter, belowground litter, and root respiration to total soil respiration in a temperate mixed hardwood forest. Can. J. For. Res. 23, 1402-1407. 
Carney, K.M., Hungate, B.A., Drake, B.G., Megonigal, J.P., 2007. Altered soil microbial community at elevated $\mathrm{CO}_{2}$ leads to loss of soil carbon. P. Natl. Acad. Sci-Biol. 104, 4990-4995.

Chen, B., Arain, M.A., Khomik, M., Trofymow, J.A., Grant, R.F., Kurz, W.A., Yeluripati, J., Wang, Z., 2013. Evaluating the impacts of climate variability and disturbance regimes on the historic carbon budget of a forest landscape. Agr. Forest Meteorol. 180, 265-280.

Conant, R.T., Ryan, M.G., Ågren, G.I., Birge, H.E., Davidson, E.A., Eliasson, P.E., Evans, S.E., Frey, S.D., Giardina, C.P., Hopkins, F.M., Hyvönen, R., Kirschbaum, M.U.F., Lavallee, J.M., Leifeld, J., Parton, W.J., Steinweg, J.M., Wallenstein, M.D., Wetterstedt, J.Å.M., Bradford, M.A., 2011. Temperature and soil organic matter decomposition rates- synthesis of current knowledge and a way forward. Glob. Change Biol. 17, 3392-3404.

Cotrufo, M.F., Ineson, P., 2000. Does elevated atmospheric $\mathrm{CO}_{2}$ concentrations affect wood decomposition? Plant Soil 224, 51-57.

Crow, S.E., Lajtha, K., Bowden, R.D., Yano, Y., Brant, J.B., Caldwell, B.A., Sulzman, E.W., 2009. Increased coniferous needle inputs accelerate decomposition of soil carbon in an old-growth forest. Forest Ecol. Manag. 258, 2224-2232.

Del Gado, I., Six, J., Peressotti, A., Cotrufo, M.F., 2003. Assessing the impact of land-use change on soil C sequestration in agricultural soils by means of organic matter fractionation and stable C isotopes. Glob. Change Biol. 9, 1204-1213.

Dickson, R.E., Coleman, M.D., Riemenschneider, D.E., Isebrands, J.G., Hogan, G.D., Karnosky, D.F., 1998. Growth of five hybrid poplar genotypes exposed to interacting elevated $\mathrm{CO}_{2}$ and $\mathrm{O}_{3}$. Can. J. For. Res. 28, 1706-1716. 
Ebanyenle, E., 2012. Effects of elevated $\mathrm{CO}_{2}$ and $\mathrm{O}_{3}$ on wood density, wood anatomical properties and decomposition of northern hardwoods. Dissertation, Michigan Technological University.

Feng, X., Simpson, A.J., Wilson, K.P., Williams, D.D., Simpson, M.J., 2008. Increased cuticular carbon sequestration and lignin oxidation in response to soil warming. Nature Geosci. 1, 836-839.

Fukami, T., Dickie, I.A., Wilkie, J.P., Park, D., Roberts, A., Buchanan, P.K., Allen, R.B., 2010. Assembly history dictates ecosystem functioning: evidence from wood decomposer communities. Ecol. Lett. 13, 675-684.

Gilbertson, R.L., 1980. Wood-rotting fungi of North America. Mycologia 72, 1-49.

Grandy,A.S., Neff, J.C., 2008. Molecular C dynamics downstream: the biochemical decomposition sequence and its impact on soil organic matter structure and function. Sci. Total Environ. 404, 297-307.

Grandy, A.S., Strickland, M.S., Lauber, C.L., Bradford, M.A., Fierer, N., 2009. The influence of microbial communities, management, and soil texture on soil organic matter chemistry. Geoderma 150, 278-286.

Hanson, C.A., Allison, S.D., Bradford, M.A., Wallenstein, M.D., Treseder, K.K., 2008. Fungal taxa target different carbon sources in forest soil. Ecosystems 11, 11571167.

Hansson, K., Kleja, D.B., Kalbitz, K., Larsson, H., 2010. Amounts of carbon mineralized and leached as DOC during decomposition of Norway spruce needles and fine roots. Soil Biol. Biochem. 42, 178-185. 
Helgason, B.L., Gregorich, E.G., Janzen, H.H., Ellert, B.H., Lorenz, N., Dick, R.P., 2014. Long-term microbial retention of residue $\mathrm{C}$ is site-specific and depends on residue placement. Soil Biol. Biochem. 68, 231-240.

Hobbie, E.A., Sanchez, F.S., Rygiewiczs, P.T., 2004. Carbon use, nitrogen use, and isotopic fractionation of ectomycorrhizal and saprotrophic fungi in natural abundance and ${ }^{13} \mathrm{C}$-labelled cultures. Mycol. Res. 108, 725-736.

Hoosebeek, M.R., Li, Y., Scarascia-Mugnozza, G.E., 2006. Free atmospheric $\mathrm{CO}_{2}$ enrichment (FACE) increased labile and total carbon in the mineral soil of a short rotation Poplar plantation. Plant Soil 281, 247-254.

Hribljan, J.A., Kane, E.S., Pypker, T.G., Chimner, R.A., 2014. The effect of longterm water table manipulations on dissolved organic carbon dynamics in a poor fen peatland. J. Geophys. Res. Biogeosci. 119, 1-19.

Huang, W., Spohn, M., 2015. Effects of long-term litter manipulation on soil carbon, nitrogen, and phosphorus in a temperate deciduous forest. Soil Biol. Biochem. 83, 12-18.

IPCC 2014. Climate change 2014: synthesis report. Cambridge University Press, Cambridge, UK and New York, NY, USA.

Janus, L.R., Angeloni, N.L., McCormack, J., Rier, S.T., Tuchman, N.C., Kelly, J.J., 2005. Elevated atmospheric $\mathrm{CO}_{2}$ alters soil microbial communities associated with trembling aspen (Populus tremuloides) roots. Microbial Ecol. 50, 102-109.

Jassal, R.S., Black, T.A., Drewitt, G.B., Novak, M.D., Gaumont-Guay, D., Nesic, Z., 2004. A model of the production and transport of $\mathrm{CO}_{2}$ in soil: predicting soil $\mathrm{CO}_{2}$ concentrations and $\mathrm{CO}_{2}$ efflux from a forest floor. Agr.Forest Meteorol. 124, 219236. 
Jorgensen, J.R., Wells. C.G., Relationship of respiration in organic and mineral soil layers to soil chemical properties. Plant Soil 39, 373-387.

Kaakinen, S., Kostiainen, K., Ek, F., Saranpää, Kubiske, M.E., Sobers, J., Karnoskys, D.F., Vapaavuori, E., 2004.. Stem wood properties of Populus tremuloides, Betula papyrifera and Acer saccharum saplings after 3 years of treatments to elevated carbon dioxide and ozone. Glob. Change Biol. 10, 1513-1525.

Kaiser, K., Guggenberger, G., 2003. Mineral surface and soil organic matter. Eur. J. Soil Sci. 54, 219-236.

Kalbitz, K., Kaiser, K., Bargholz, J., Dardenne, P., 2006. Lignin degradation controls the production of dissolved organic matter in decomposing foliar litter. Eur. J. Soil Sci. 57, 504-516.

King, J.S., Pregitzer, K.S., Zak, D.R., Sober, J., Isebrands, V.G., Dickson, R.E., Hendrey, G.R., Karnosky, D.F., 2001. Fine-root biomass and fluxes of soil carbon in young stands of paper birch and trembling aspen as affected by elevated atmospheric $\mathrm{CO}_{2}$ and tropospheric $\mathrm{O}_{3}$. Oecologia 128, 237-250.

King, J.S., Hanson, P.J., Bernhardt, E., Deangeliss, P., Norby, R.J., Pregitzer, K.S., 2004. A multiyear synthesis of soil respiration responses to elevated atmospheric $\mathrm{CO}_{2}$ from four forest FACE experiments. Glob. Change Biol. 10, 1027-1042.

Kirschbaum, M.U.F., 1995. The temperature dependence of soil organic matter decomposition, and the effect of global warming on soil organic C storage. Soil Biol. Biochem. 27, 753-760.

Leavitt, S.W., Pendall, E., Paul, E.A., Brooks, T., Kimball, B.A., Pinter, P.J., Johnson, H.B., Matthias, A., Wall, G.W., LaMorte, R.L., 2001. Stable-carbon isotopes and 
soil organic carbon in wheat under CO2 enrichment. New Phytol. 150, 305-314.

Leff, J.W., Wieder, W.R., Taylor, P.G., Townsend, A.R., Nemergut, D.R., Grandy, A.S., Cleveland, C.C., 2012. Experimental litterfall manipulation drives large and rapid changes in soil carbon cycling in a wet tropical forest. Glob. Change Biol. 18, 2969-2979.

Loya, W.M., Pregitzer, K.S., Karberg, N.J., King, J.S., Giardina, C.P., 2003. Reduction of soil carbon formation by tropospheric ozone under increased carbon dioxide levels. Nature 425, 705-707.

Marion, G.M., Henry, G.H., Freckman, D.W., Johnstone, J., Jones, G., Jones, M.H., Lévesque, E., Molau, U., Mølgaard, P., Parsons, A.N., Svoboda, J., Virginia, R.A., 1997. Open-top designs for manipulating field temperature in high-latitude ecosystems. Glob. Change Biol. 3, 20-32.

Melillo, J.M., Aber, J.D., Muratore, J.F., 1982. Nitrogen and lignin control of hardwood leaf litter decomposition dynamics. Ecology 63, 621-626.

Melillo, J.M., Steudler, P.A., Aber, J.D., Newkirk, K., Lux, H., Bowles, F.P., Catricala, C., Magill, A., Ahrens, T., Morrisseau, S., 2002. Soil warming and carbon-cycle feedbacks to the climate system. Science 298, 2173-2176.

Niklaus, P.A., Falloon, P., 2006. Estimating soil carbon sequestration under elevated $\mathrm{CO} 2$ by combining carbon isotope labelling with soil carbon cycle modelling. Glob. Change Biol. 12, 1909-1921.

Osono, T., 2007. Ecology of ligninolytic fungi associated with leaf litter decomposition. Ecol. Res. 22, 955-974. 
Palviainen, M., Finér, L., Kurka, A.-M., Mannerkoski, H., Piirainen, S., Starr, M., 2004. Decomposition and nutrient release from logging residues after clear-cutting of mixed boreal forest. Plant Soil 262, 53-67.

Pandey, K.K., Pitman, A.J., 2003. FTIR studies of the changes in wood chemistry following decay by brown-rot and white-rot fungi. Int. Biodeter. Biodegr. 52, 151-160.

Pandey, K.K., Nagveni, H.C., 2007. Rapid characterization of brown and white rot degraded chir pine and ruberwood by FTIR spectroscopy. Holz Roh-Werkst 65, 477-481.

Phillips, R.L., Zak, D.R., Holmes, W.E., White, D.C., 2002. Microbial community composition and function beneath temperate trees exposed to elevated atmospheric carbon dioxide and ozone. Oecologia 131, 236-244.

Pregitzer, K.S., Burton, A.J., King, J.S., Zak, D.R., 2008. Soil respiration, root biomass, and root turnover following long-term exposure of northern forests to elevated atmospheric $\mathrm{CO}_{2}$ and tropospheric $\mathrm{O}_{3}$. New Phytol. 180, 153-161.

Preston, C.M., Trofymow, J.A., Niu, J., Fyfe, C.A., 1998. ${ }^{13}$ CPMAS-NMR spectroscopy and chemical analysis of coarse woody debris in coastal forests on Vancouver Island. Forest Ecol. Manag. 111, 51-68.

Preston, C.M., Trofymow, J.A., Flanagan, L.B. Decomposition, 2006. delta C-13, and the “lignin paradox”. Can. J. Soil Sci. 86, 235-245.

Raich, J.W., Schlesinger, W.H., 1992. The global carbon dioxide flux in soil respiration and its relationship to vegetation and climate. Tellus 44, 81-99. 
Rasse, D.P., Longdoz, B., Ceulemans, R., 2001. TRAP: a modelling approach to belowground carbon allocation in temperate forests. Plant Soil 229, 281-293.

Rasse, D.P., Rumpel, C., Dignac, M.-F., 2005. Is soil carbon mostly root carbon? Mechanisms for a specific stabilisation. Plant Soil 269, 341-356.

Runion, G.B., Entry, J.A., Prior, S.A., Mitchell, R.J., Rogers, H.H. 1999. Tissue chemistry and carbon allocation in seedlings of Pinus palustris subjected to elevated atmospheric $\mathrm{CO}_{2}$ and water stress. Tree Physiol. 19, 329-335.

Santruckova, H., Bird, M.I., Lloyd, J., 2000. Microbial processes and carbon-isotope fractionation in tropical and temperate grassland soils. Funct. Ecol. 14, 108-114.

Sayer, E.J., 2006. Using experimental manipulation to assess the roles of leaf litter in the functioning of forest ecosystems. Biol. Rev. 81, 1-31.

Schlesinger, W.H., 1977. Carbon balance in terrestrial detritus. Ann. Rev. Ecol. Syst. 8, 51-81.

Singh, J.S., Gupta, S.R., 1977. Plant decomposition and soil respiration in terrestrial ecosystems. Bot. Rev. 43, 499-528.

Sulzman, E.W., Brant, J.B., Bowden, R.D., Lajtha, K., 2005. Contribution of aboveground litter, belowground litter, and rhizosphere respiration to total soil $\mathrm{CO}_{2}$ efflux in an old growth coniferous forest. Biogeochemistry 73, 231-256.

Talhelm, A.F., Pregitzer, K.S., Zak, D.R., 2009. Species-specific responses to atmospheric carbon dioxide and tropospheric ozone mediate changes in soil carbon. Ecol. Lett. 12, 1219-1228. 
Trumbore, S., 2009. Radiocarbon and soil carbon dynamics. Annu. Rev. Earth Planet. Sci. 37, 47-66.

Taylor, B.R., Parkinson, D., Parsons, W.F.J., 1989. Nitrogen and lignin content as predictors of litter decay rates: a microcosm test. Ecology 70, 97-104.

Von Lützow, M., Kögel-Knaber, I., Ekschmitt, K., Matzner, E., Guggenberger, G., Marschner, B., Flessa, H., 2006. Stabilization of organic matter in temperate soils: mechanisms and their relevance under different soil conditions-a review. Eur. J. Soil Sci. 57, 426-445.

Wang, C., Yang, J., Zhang, Q., 2006. Soil respiration in six temperate forests in China. Glob. Change Biol. 12, 2103-2114.

Xu, G., Wang, L., Liu, J., Wu, J., 2013. FTIR and XPS analysis of the changes in bamboo chemical structure decayed by white-rot and brown-rot fungi. Appl. Surf. Sci. 280, 799-805.

Zak, D.R., Pregitzer, K.S., Curtis, P.S., Teeri, J.A., Fogel, R., Randlett, D.L., 1993. Elevated atmospheric $\mathrm{CO}_{2}$ and feedback between carbon and nitrogen cycles. Plant Soil 151, 105-117. 